\title{
IMPLEMENTACIÓN Y ÁNALISIS DE UN PROTOTIPO DE GENERACIÓN Y ALMACENAMIENTO DE ENERGÍA ELÉCTRICA A PARTIR DEL MOVIMIENTO DE UNA BICICLETA COMO PROPUESTA PARA LA DISMINUCIÓN DEL CONSUMO ENÉRGETICO EN LA ESCUELA DE LA COMUNIDAD EL ARROYO: ETAPA INICIAL
}

\author{
Presentado por: \\ Diana Lizeth Gutiérrez Roa
}

Tutor:

Andrea Katherine Pérez

Docente de la Facultad de Ingeniería Electrónica 


\section{TABLA DE CONTENIDO}

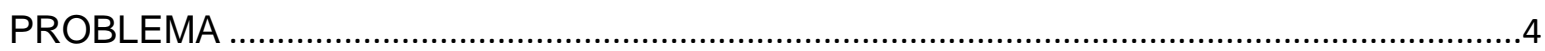

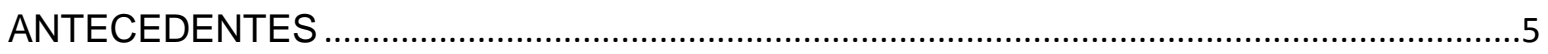

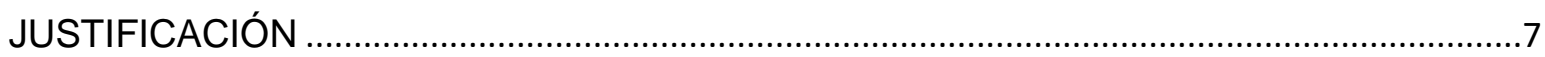

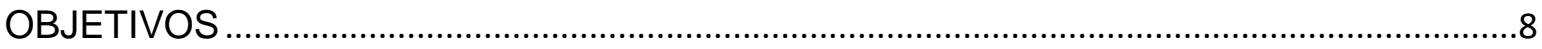

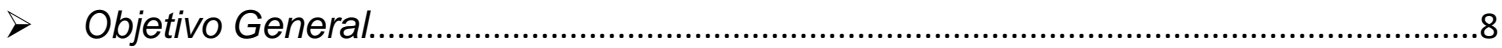

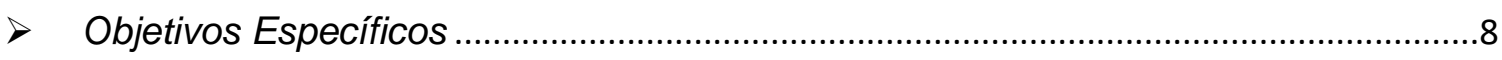

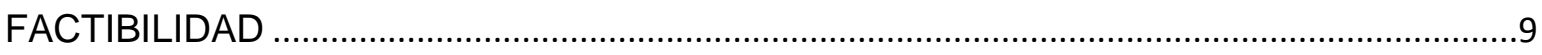

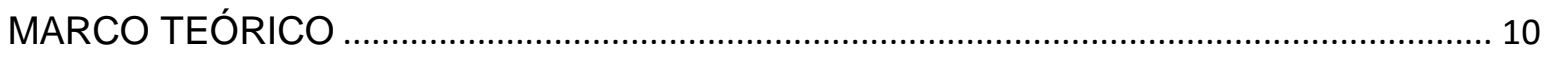

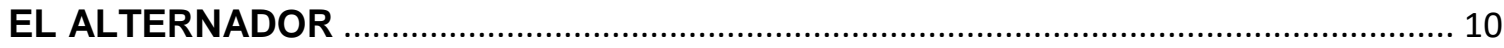

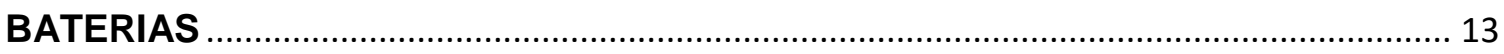

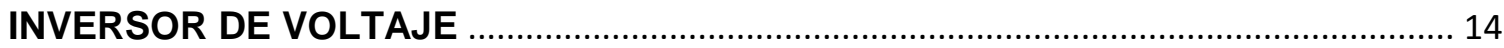

GENERALIDADES DE LA GENERACIÓN ELÉCTRICA A PARTIR DE BICICLETAS ESTATICAS

Mecánica del sistema de generación ............................................................. 16

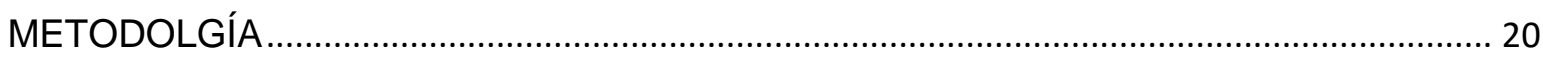

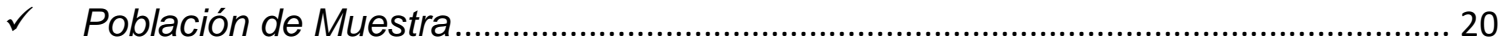

$\checkmark \quad$ Técnica de recolección de datos ................................................................................ 20

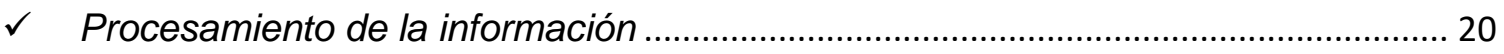

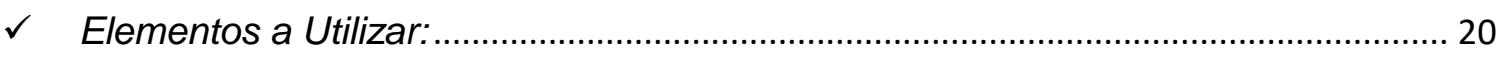

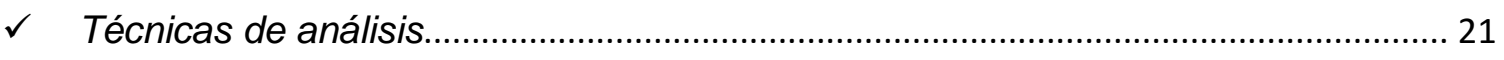

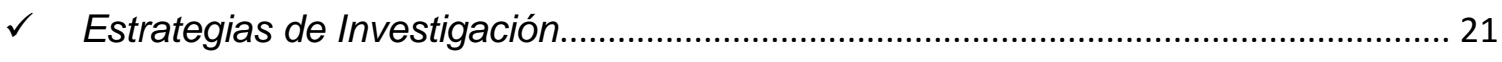

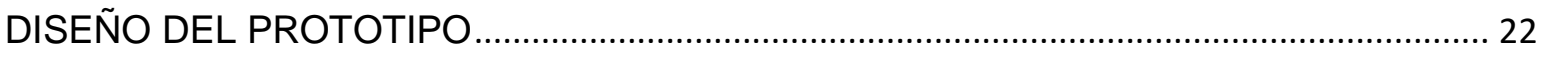

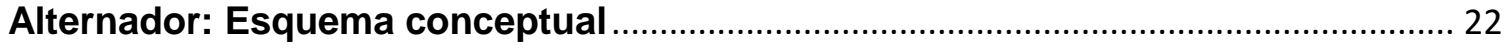

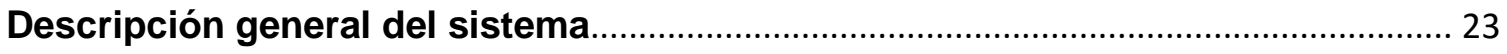

Alternador: Esquema de sistema implementado ................................................... 24

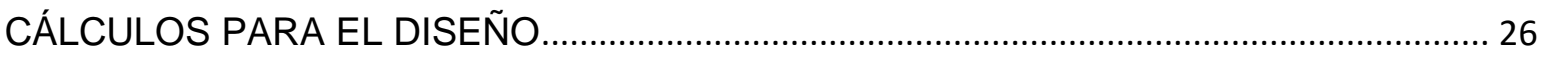

REVOLUCIONES POR MINUTO (RPM) EN EL EJE DEL ALTERNADOR .................. 26

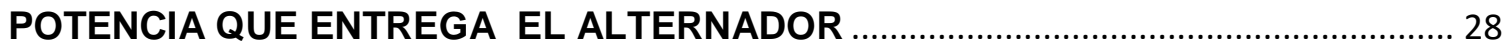

POTENCIA PROMEDIO GENERADA POR UNA PERSONA .................................... 29 


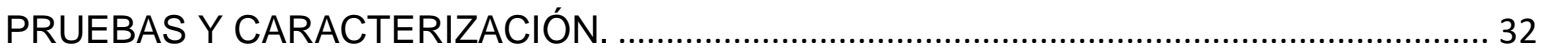

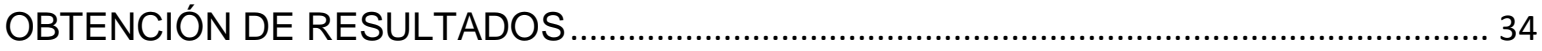

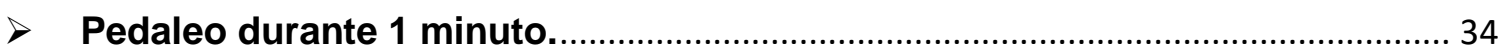

$>$ Pedaleo durante un tiempo mayor a 15 minutos................................................ 34

$>$ Tiempo de duración de la batería con diferentes dispositivos. ........................... 38

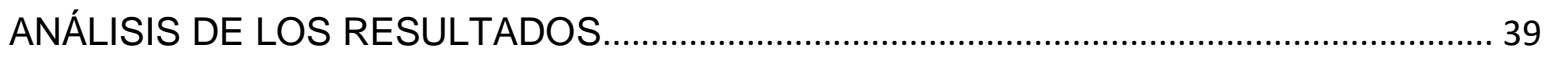

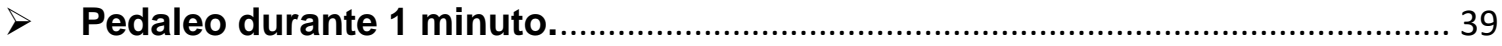

$>$ Pedaleo durante un tiempo mayor a 15 minutos................................................... 40

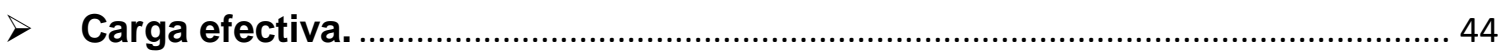

$>$ Descarga batería de almacenamiento. ..................................................................... 45

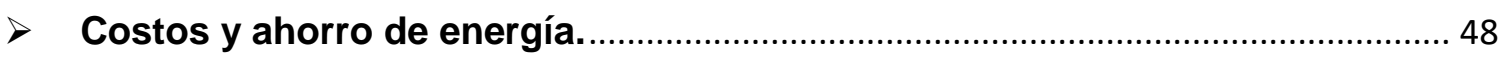

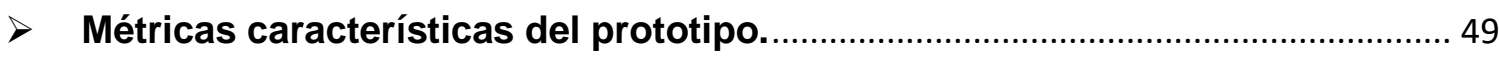

$>$ Tabla comparativa con otras fuentes de energía................................................ 50

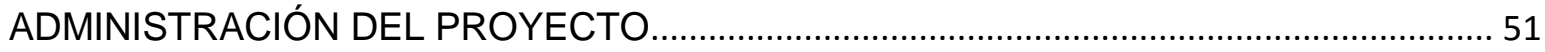

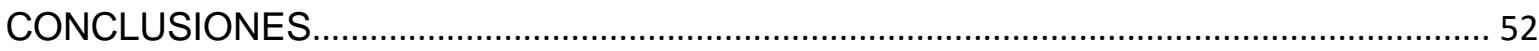

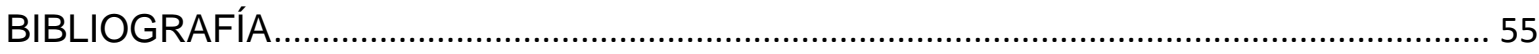

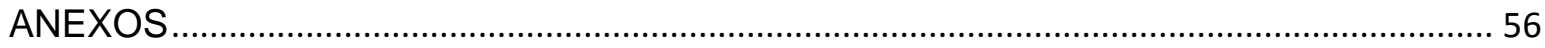




\section{PROBLEMA}

La Universidad Santo Tomás ha identificado durante los últimos años comunidades que presentan necesidades en bienestar social, las cuales pueden ser mitigadas a través de la ejecución de proyectos con enfoque social que son llevados a cabo por los diferentes estudiantes de las facultades de la Universidad.

Específicamente, en la comunidad el Arroyo - Cazucá, se ha detectado la necesidad de capacitar y generar espacios de esparcimiento a los niños y adultos, para lo cual se debe hacer uso de las diferentes instalaciones construidas con el objetivo de brindar apoyo a las familias desplazadas que conforman la comunidad. Sin embargo, es necesario mencionar que la comunidad depende en gran medida de las donaciones de otras entidades, siendo así difícil sostener dichas instalaciones por el costo que generan algunos de los servicios públicos indispensables para su funcionamiento, como es el caso de la energía eléctrica.

Partiendo de esa necesidad, es posible aplicar los desarrollos tecnológicos que actualmente se han generado en torno a la producción de energía a partir de recursos renovables; más aún cuando los recursos no renovables empleados para generar energía han escaseado en mayor proporción durante los últimos años, haciendo muy costosa la generación de la misma y deteriorando el medio ambiente. Teniendo en cuenta esto, se evidencia que el aprovechamiento de energías alternativas provee una solución adecuada a la necesidad que se presenta en la comunidad El Arroyo con respecto al consumo de energía eléctrica para el funcionamiento de las instalaciones físicas. Proponiendo como posible solución desarrollar un prototipo con el cual se pueda almacenar energía producida a partir del pedaleo de una bicicleta, para que posteriormente sea suministrada en la escuela de la comunidad. 


\section{ANTECEDENTES}

El sector de Altos de Cazucá se ha convertido, desde hace aproximadamente una década, en uno de los lugares del país con mayor población en situación de desplazamiento y vulnerabilidad. Las familias allí asentadas deben comenzar a reorganizar sus vidas en un lugar marginal que no presenta las condiciones mínimas para acceder a un nivel de vida digno.

La comunidad siempre está abierta para acoger a estas familias, uniéndolos la misma situación de pobreza y desplazamiento y eso los hace solidarios unos con otros.

Pero en los hogares Colombianos, así como en las instalaciones de la comunidad El Arroyo; es un gran problema los costos que generan en la factura el alumbrado y la conexión de algunos equipos electrónicos, donde capacitan y dan espacios de esparcimiento a estas personas y familias que permita un ambiente reconfortable afianzando aptitudes y adquiriendo mayores conocimientos.

Estos son los proyectos, que apoyados por algunas fundaciones, se han desarrollado en la comunidad El Arroyo durante cinco años:

1. La construcción de la escuela en el año 2000: actualmente se cuenta con cuatro aulas que acogen a 300 niños en dos jornadas

2. El comedor escolar en el año 2001: actualmente reciben desayuno y almuerzo 220 niños que pagan la simbólica suma $\$ 300$ diarios.

3. Jardín Infantil en el año 2003: actualmente asisten al jardín 60 niños, de 8 am a $4 \mathrm{pm}$. Se les ofrece desayuno, almuerzo y refrigerio y los que pueden cancelan $\$ 500$ pesos diarios.

4. Capilla San Pedro de El Arroyo: un grupo de personas se reunieron para conformar el Comité de la Capilla y ellos desarrollan programas sociales de diversa índole. Además está abierta para realizar allí reuniones y cursos ya que no cuenta ni siquiera con una sede comunal.

5. Cancha múltiple. Marzo de 2005. 
6. Comedor para la tercera edad, "El remanso de los abuelos", en 2005. ${ }^{[1]}$

Adicionalmente hoy en día se encuentran proyectos relacionados en diversos países, uno de estos se encuentra en Estados Unidos y consiste en un gimnasio que obtiene electricidad a partir del ejercicio que los clientes realizan en las bicicletas estáticas. Adam Boesel, dueño del gimnasio Green Microgym de Alberta en el estado de Oregón, ha diseñado unas bicicletas estáticas que gracias a un generador adaptado a ellas, convierten en electricidad la energía que los clientes producen al pedalear. La mayoría de los usuarios generará entre 50 y 150 vatios mientras se ejercitan durante media hora, lo cual es suficiente energía para alimentar un teléfono móvil durante una semana. La energía es almacenada y usada para ayudar a accionar luces, ventiladores, equipo de música y televisores de pantalla plana. Boesel, citado por TheDaily Mail, dice que en 2009 el gimnasio generó $36 \%$ de la energía que consumí. [2]

\footnotetext{
${ }^{1}$ http://www.saliendodelcallejon.pnud.org.co/img upload/1433f8d9ffdce21262b034f353875ed6/cron altoscazuca.pdf

${ }^{2}$ http://www.mercadofitness.com/blog/noticias/the-green-microgym-un-gimnasio-norteamericano-que-piensa-en-verde/
} 


\section{JUSTIFICACIÓN}

La comunidad El Arroyo localizado en Cazucá, cuenta con una infraestructura donde se capacita a niños y adultos de diferentes edades, además de una escuela que cuenta con un parque de juegos para actividades lúdicas y de esparcimiento para los niños. Pero mantener estas instalaciones genera un costo elevado en sus facturas de energía.

Por tanto, es necesario implementar un proyecto que aporte una solución a este problema de consumo energético para lo cual se propone desarrollar un prototipo de energía renovable basado en la actividad física que los niños y adultos de la escuela pueden desarrollar en una bicicleta; ayudando a generar energía para que pueda ser almacenada y posteriormente aprovechada en las instalaciones de la escuela, de manera que en un futuro pueda disminuir en cierta medida el costo que genera mantener la iluminación de dichas instalaciones, además de promover las actividades físicas para mejorar y mantener un estado saludable en las personas que hacen uso de este proyecto.

Sin embrago, el desarrollo de esa solución implica generar, almacenar y distribuir la energía eléctrica y para cada uno de estos procesos se requiere un análisis profundo de los factores que intervienen, de manera que pueda asegurarse el buen desarrollo del prototipo final. Es por esta razón que se plantea dividir la implementación de la solución en dos etapas: una etapa inicial que incluye la implementación y caracterización de un prototipo para la generación y almacenamiento de energía, etapa que será desarrollada a lo largo de este trabajo de grado y una etapa final o trabajo futuro en el cual se realizara el proceso de distribución de dicha energía. 


\section{OBJETIVOS}

\section{$>$ Objetivo General}

Implementar y analizar el funcionamiento de un prototipo para la generación y almacenamiento de energía eléctrica a partir del pedaleo en una bicicleta.

\section{$>$ Objetivos Específicos}

- Implementar un prototipo a partir de una bicicleta que permita generar energía eléctrica.

- Integrar al prototipo que genera la energía una etapa de almacenamiento mediante el uso de baterías.

- Realizar pruebas de desempeño que permitan obtener la información necesaria para caracterizar el funcionamiento del prototipo.

- Determinar las métricas de comparación y funcionamiento de acuerdo a los resultados de las pruebas de desempeño.

- Evaluar de acuerdo a las métricas del prototipo la eficiencia con respecto a otros sistemas de generación de energía eléctrica.

- Vislumbrar el impacto para la población en términos de calidad de vida. 


\section{FACTIBILIDAD}

Dado que la Universidad Santo Tomas, forma profesionales que se interesen por dar un apoyo integral a la sociedad, encontramos que la Comunidad El Arroyo, no cuenta con los suficientes recursos para mantener el consumo elevado de la energía que genera mantener cada una de sus infraestructuras donde cuenta con una escuela, una sala de computo, un comedor comunitario, entre otras; como Ingenieros Electrónicos de la Universidad Santo Tomas, estamos en la capacidad, en base a los conocimientos, de desempeñarnos en las diferentes áreas que se nos requiera; por tanto para aportar un mejoramiento a esta necesidad que presentan, contamos con el apoyo y colaboración de profesores con amplios conocimientos acorde con los objetivos de este proyecto.

Para la implementación y desarrollo de esta propuesta contamos con la facilidad de encontrar los materiales requeridos en el mercado, para ello se espera contar con los recursos aportados por parte del Centro de Proyección social de la Universidad Santo Tomas. Por otra parte, podemos decir que la implementación del prototipo no genera mayor riesgo para la población, ya que se basa en el pedaleo de una bicicleta y la etapa de almacenamiento, durante el proceso de pruebas, estará bajo la coordinación de la persona encargada de la ejecución del proyecto y al terminar la etapa de pruebas el prototipo deberá contar con las medidas de seguridad necesarias para evitar posibles accidentes. 


\section{MARCO TEÓRICO}

\section{EL ALTERNADOR}

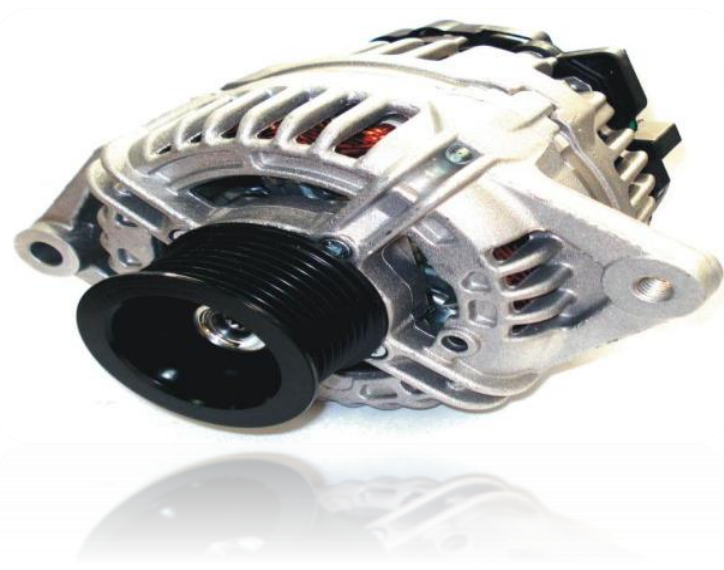

Imagen tomada de "El alternador. Principio de funcionamiento." [3]

El alternador es el elemento del circuito eléctrico del automóvil que transforma la energía mecánica en energía eléctrica, proporcionando así un suministro eléctrico durante la marcha del vehículo. El alternador en un vehículo debe estar diseñado para proporcionar corriente eléctrica necesaria para la carga de la batería así como suministrar corriente a todos los demandantes eléctricos que lo requieran.

El alternador está conformado por:

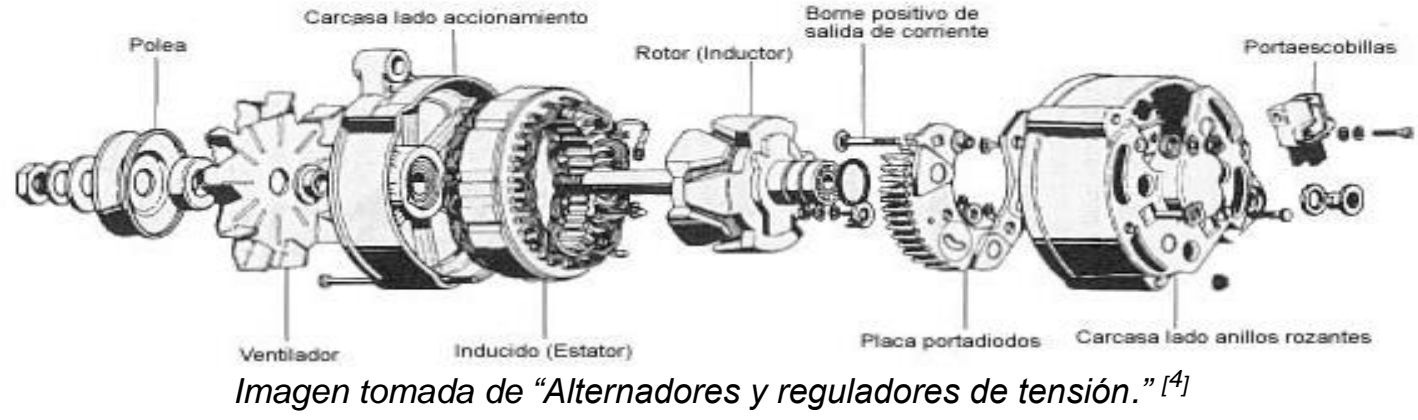

${ }^{3} \mathrm{http}: / /$ professionalautomotive.wordpress.com/2012/06/30/el-alternador-principio-de-funcionamiento/

4 http://www.aficionadosalamecanica.net/alternador-funcionam.htm 


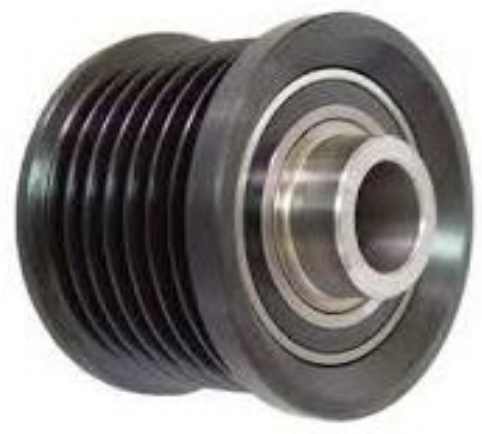

- Polea: Es la que recibe la fuerza mecánica procedente del motor térmico de combustión a través de una correa. Esta polea va enganchada al eje del alternador que mueve el rotor que hay en su interior y arrastra también al ventilador, situado en el interior en los alternadores de última generación.

- Rotor (Inductor): es la parte móvil del alternador, encargado de crear el campo magnético inductor el cual provoca en el bobinado inducido la corriente eléctrica que suministra después el alternador. [imagen tomada de: Alternadores y reguladores de tensión. $\left.{ }^{[4]}\right]$
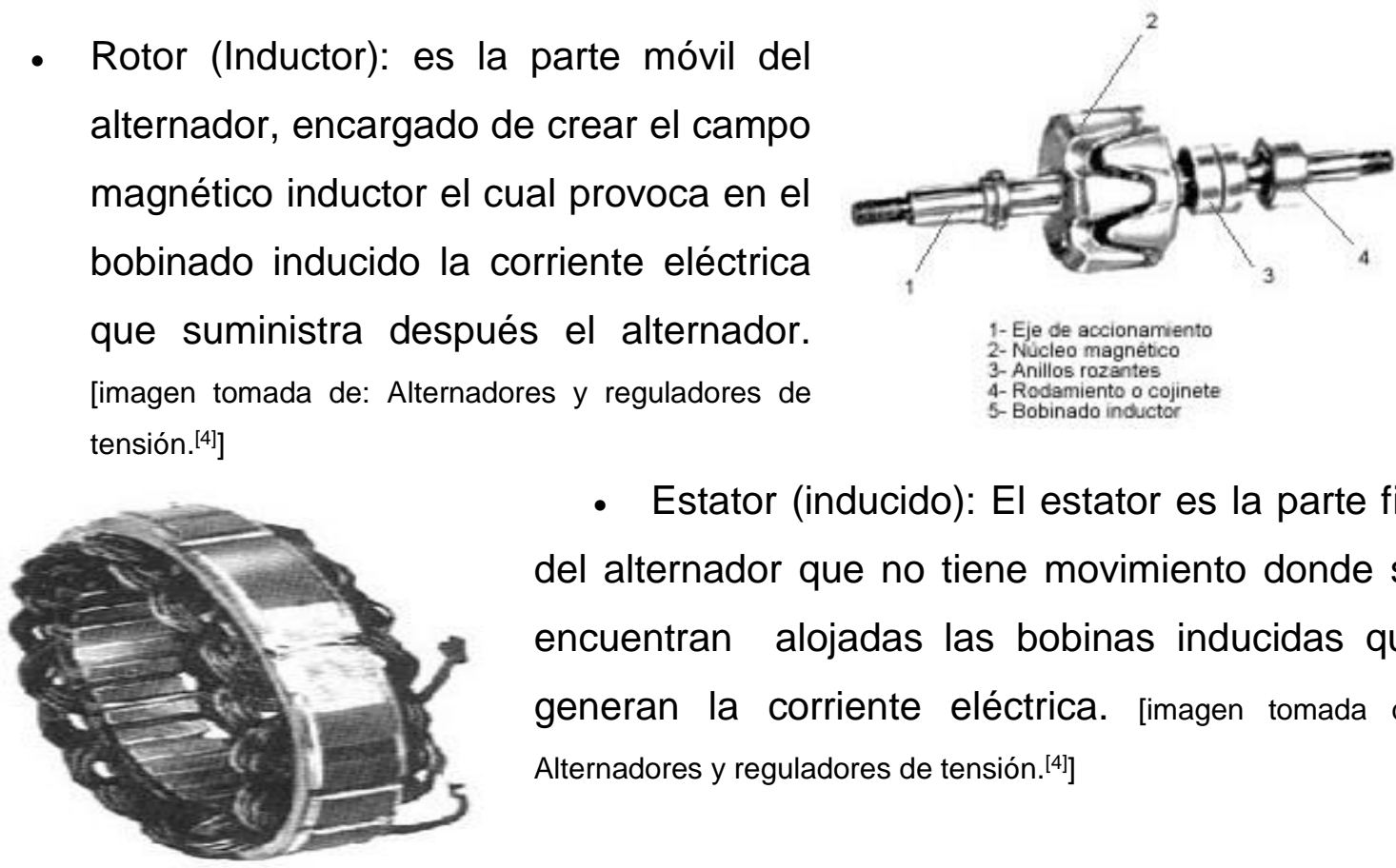

- Estator (inducido): El estator es la parte fija del alternador que no tiene movimiento donde se encuentran alojadas las bobinas inducidas que generan la corriente eléctrica. [imagen tomada de: Alternadores y reguladores de tensión. $\left.{ }^{[4]}\right]$

- Puente rectificador de diodos: Es el elemento encargado de rectificar la corriente de salida del alternador ya que esta es alterna, haciendo que ésta se convierta en continua y sea factible para el uso en el automóvil. [imagen tomada de: Alternadores y reguladores de tensión. $\left.{ }^{[4]}\right]$

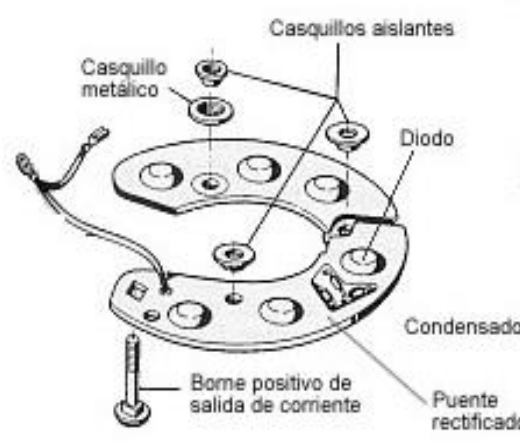




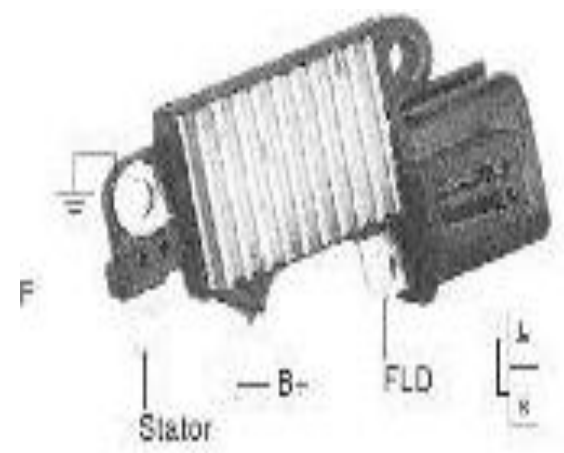

- Regulador: es el encargado de mantener una tensión máxima de salida del alternador de 14.5 voltios. A mayor rpm mayor campo magnético y a su vez se produce más voltaje, es por eso que a más revoluciones suministra menos corriente al rotor (Inductor). [imagen tomada de: Alternadores y reguladores de tensión. $\left.{ }^{[4]}\right]$

- Carcasa lado de anillos rozantes: Es una pieza de aluminio obtenida por fundición, donde se monta el porta escobillas, fijado a ella por tornillos. De esta misma carcasa salen los bornes de conexión del alternador y en su interior se aloja el cojinete que sirve de apoyo al extremo del eje del rotor. En su cara frontal hay practicadas unos orificios, que dan salida o entrada a la corriente de aire provocada por el ventilador.

- Carcasa lado de accionamiento: En su interior se aloja el otro cojinete de apoyo del eje del rotor. En su periferia lleva unas bridas para la sujeción del alternador al motor del vehículo y el tensado de la correa de arrastre. Las dos carcasas aprisionan el estator y se unen por medio de tornillos, quedando en su interior alojado el estator y el rotor, así como el puente rectificador.

- Ventilador: Los componentes del alternador experimentan un considerable aumento de la temperatura debido, en gran parte, a las pérdidas de calor del alternador y a la entrada de calor procedente del compartimento motor. La temperatura máxima admisible es de 80 a $100^{\circ} \mathrm{C}$, según el tipo de alternador. Debido a que los ventiladores son accionados junto con el eje del alternador, al aumentar la velocidad de rotación se incrementa también la proporción de aire fresco. Así se garantiza la refrigeración para cada estado de carga. 


\section{BATERIAS}

Una batería eléctrica o también denominada acumulador eléctrico, es un dispositivo que permite almacenar energía eléctrica, usando procedimientos electroquímicos y que posteriormente la devuelve casi en su totalidad; este ciclo puede repetirse por un determinado número de veces.

\section{Tipos de Baterías}

- Baterías Primarias: transforman la energía química en energía eléctrica, de manera irreversible, es decir al agotarse su energía almacenada son desechadas; entre estas encontramos las pilas alcalina.

- Baterías Secundarias: Pueden revertir sus reacciones químicas mediante el suministro de energía eléctrica a la celda, hasta el restablecimiento de su composición original; entre estas podemos encontrar las baterías de ácidoplomo usada en los vehículos; las baterías de lones de litio usada en los dispositivos electrónicos portátiles, y las pilas recargables de Ni-HM.

\section{Principio de funcionamiento de una Batería de plomo acido}

Estas baterías están compuestas por un ánodo de plomo esponjoso $(\mathrm{Pb})$ y un cátodo de dióxido de plomo ( $\mathrm{PbO} 2)$ que se encuentran sumergidas en una determinada concentración de ácido sulfúrico (H2SO4).

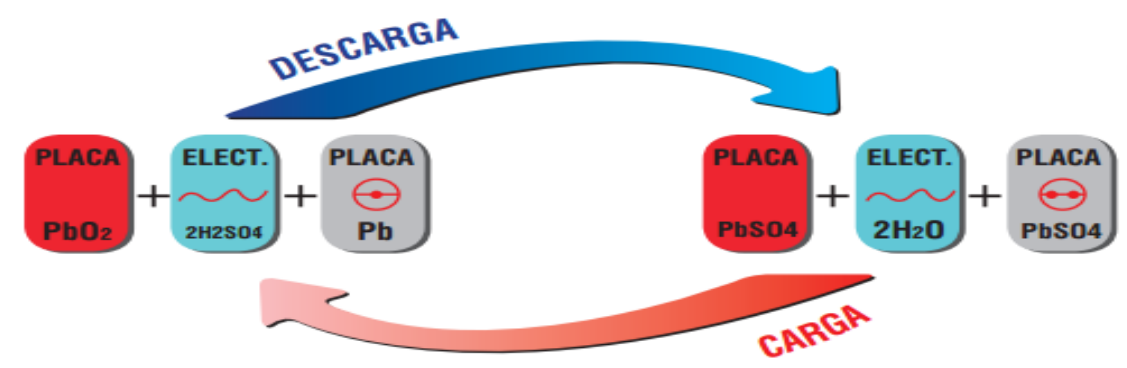

Imagen tomada de: Manual de acumuladores eléctricos de plomo-ácido para Auto elevadores. [5]

\footnotetext{
${ }^{5}$ http://www.bateriascarpinelli.com.ar/carpinelli/manual_folder/MMBVer50527_AF.pdf
} 


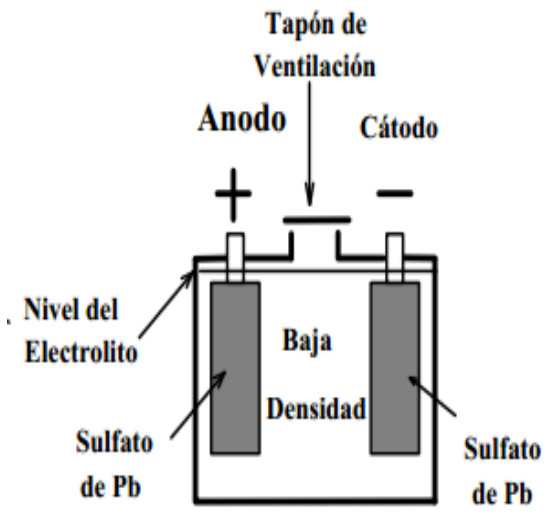

- Funcionamiento en descarga: Cuando la batería se encuentra en esta etapa, se produce una corriente a través de los cambios químicos, donde el peróxido de plomo cede el oxígeno y se combina con el ácido sulfúrico, formando el sulfato de plomo (PbSO4). De igual forma, el plomo esponjoso también se combina con el ácido sulfúrico formando el sulfato de plomo. [imagen tomada de: La batería de plomo - acido. $\left.{ }^{[6]}\right]$

- Funcionamiento en carga: Cuando la batería se encuentra en esta etapa, el sulfato de plomo de la placa positiva se convierte en plomo peróxido de plomo y el sulfato de plomo de la placa negativa se convierte en plomo esponjoso. [imagen

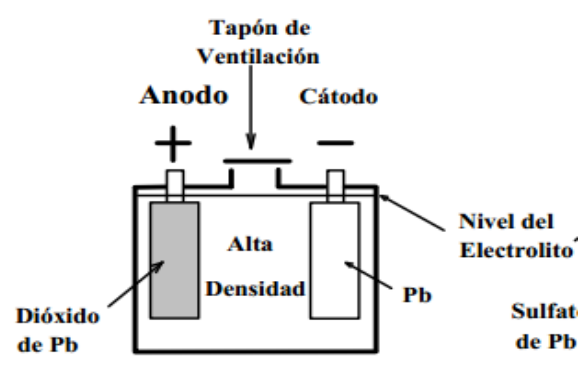
tomada de: La batería de plomo - acido.[6]]

\section{INVERSOR DE VOLTAJE}

El inversor de voltaje es un sistema que convierte la tensión de corriente continua, en un voltaje simétrico de corriente alterna, que puede ser de $220 \mathrm{~V}$ o $120 \mathrm{~V}$.

El inversor considera dos etapas:

Sintetizadora: en esta etapa se produce una onda de impulsos a partir de una tensión DC.

Filtradora: esta etapa se ocupa de eliminar los armónicos no deseados de la onda de impulsos para tener en su salida una señal senoidal.

\footnotetext{
${ }^{6}$ http://www.olajedatos.com/documentos/baterias_plomo.pdf
} 
Su funcionamiento se basa en un transformador, por el cual pasa una corriente continua, que pasa en un sentido y luego en el otro.

A medida que la corriente pasa a través de la cara primaria del transformador, la polaridad cambia 120 veces cada segundo. Como consecuencia, la corriente que sale del secundario del transformador va alternándose, con una frecuencia de 60 ciclos completos por segundo.

\section{GENERALIDADES DE LA GENERACIÓN ELÉCTRICA A PARTIR DE BICICLETAS ESTATICAS}

El acondicionamiento físico a partir de bicicletas estáticas permite un mejoramiento en el metabolismo, en el sistema cardiovascular y respiratorio, una quema significativa de calorías y aumenta la tonicidad y la masa muscular de caderas, glúteos, piernas, pantorrillas y abdomen; además, de un beneficio emocional (reduce el estrés). ${ }^{[7]}$

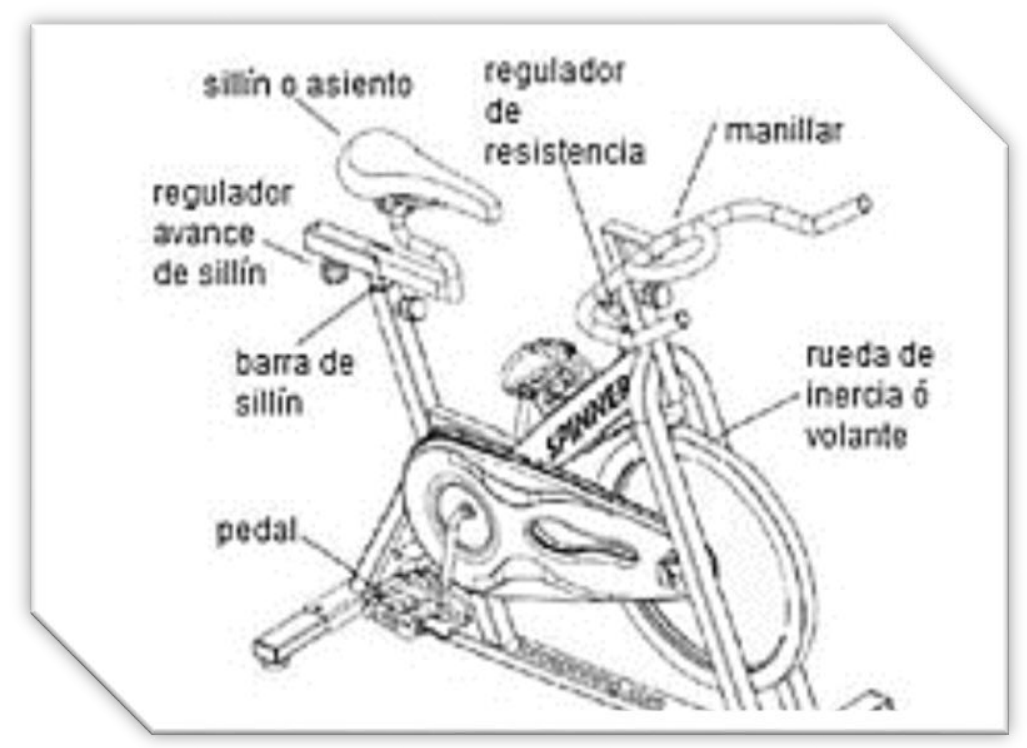

Imagen tomada de "Diseño de un sistema degeneración de energía eléctrica a partir de bicicletas estática" por Karl Von Drais y Thomas McCal. ${ }^{[7]}$

\footnotetext{
7 Proyecto: "Diseño de un sistema degeneración de energía eléctrica a partir de bicicletas estática" por Karl
} Von Drais y Thomas McCal. 


\section{Mecánica del sistema de generación}

El funcionamiento mecánico de la bicicleta requiere un simple impulso de un par de pedales con las piernas (parte del cuerpo humano que tiene mayor potencia muscular). Este esfuerzo puede ajustarse a partir de un sistema de fricción manual, denominado regulador de resistencia.

Poseen una rueda de inercia o volante de varios kilogramos, a fin de facilitar el pedaleo, y que para efectos del sistema a diseñarse, es la parte de contacto a partir de la cual se transmitirá la energía de la bicicleta al generador DC.

La potencia promedio generada por una persona promedio en una bicicleta oscila entre $270 \mathrm{~W}$ a $400 \mathrm{~W}$. La siguiente Figura ilustra la dinámica de pedaleo de un tripulante. ${ }^{[4]}$

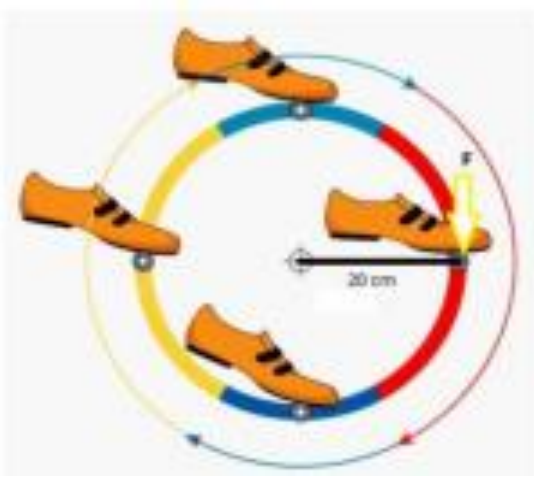

Imagen tomada de "Diseño de un sistema degeneración de energía eléctrica a partir de bicicletas estática" por Karl Von Drais y Thomas McCal. ${ }^{[7]}$

El par generado por la fuerza ejercida en el pedaleo está dado por:

$$
\mathrm{T}=\mathrm{F} \times \mathrm{d}
$$

La fuerza promedio que pueden aplicar los adultos, sin distinión de sexo es de 294,3 N. ${ }^{[7]}$

\section{Calculo gasto calórico $30 \mathrm{~min}$ de pedaleo}

$0,046 \times$ (tu peso $\mathrm{Kg} \times 2,2) \times$ total de minutos de práctica $=$ Kilocalorías quemadas aproximadas

Por ejemplo: si pesas $60 \mathrm{Kg}$ y practicas un ejercicio durante 30 minutos la fórmula quedaría: 
$0,046 \times(60 \times 2,2) \times 30=0,046 \times 132 \times 30=182,16$ kilocalorías aproximadas quemadas

Con esta fórmula puesta anteriormente, podrás calcular las calorías quemadas en un tiempo determinado. Mientras más pedalees, más calorías quemas, por lo tanto más rápido cargaras la batería. ${ }^{[8]}$

\section{ENERGIAS RENOVABLES}

Este tipo de energías son las que se aprovechan directamente de los recursos que se consideran inagotables, como el sol, el viento, entre otros.

Actualmente, la dependencia del petróleo, del gas y del carbón, ha generado conflictos medioambientales debido a la escasez debido a la mala administración con la que se han venido manejando.

Por esta razón, en los últimos años se ha hecho necesario invertir en el desarrollo y aplicación de tecnologías alternativas de producción de energía que funcionen con recursos renovables. Además, en el mundo entero el término renovable se asocia con un medio ambiente más limpio, apropiado para nosotros y las futuras generaciones. Actualmente las energías renovables cubren cerca del $20 \%$ del consumo mundial de electricidad.

${ }^{8}$ http://www.mienergiagratis.com/proyectos/22.pdf 
Las energías renovables se han clasificado en seis grupos principales:

\begin{tabular}{|c|c|c|c|}
\hline RECURSO & TECNOLOGIA & ELEMENTOS & APLICACIONES \\
\hline \multirow{3}{*}{ SOLAR } & Fotovoltaica & Celdas solares & Electricidad \\
\hline & Termica & Colectores & Calor, electricidad \\
\hline & Pasiva & $\begin{array}{l}\text { Muros, ventanas, } \\
\text { etc }\end{array}$ & Calor, iluminacion \\
\hline \multirow{2}{*}{ EOLICA } & Generacion electrica & Aerogenerdores & Electricidad \\
\hline & Fuerza motriz & Aerobombeo & Fuerza motriz \\
\hline \multirow{7}{*}{ BIOMASA } & Digestion anaerobia & Biodigestion & Biogas combustible \\
\hline & Gasificacion & Gasificador & Gas combustible \\
\hline & Pirolisis & Pirolisador & Combustible \\
\hline & Fermantacion & Destilleria & Bioetanol \\
\hline & Alcoholica & & \\
\hline & Esterificacion & $\begin{array}{l}\text { Unidad de } \\
\text { esterificacion }\end{array}$ & Biodiesel \\
\hline & Combustion & Hornos, calderas & Calor, electricidad \\
\hline \multirow{3}{*}{ HIDRAULICA } & Centrales & Pequeñas centrales & Electricidad \\
\hline & Hidroelectricas & Hidraulica & \\
\hline & $\begin{array}{l}\text { Pequeños } \\
\text { aprovechamientos }\end{array}$ & Rueda & Fuerza motriz \\
\hline \multirow{4}{*}{ OCEANOS } & Mareas & Barreras, turbinas & Electricidad \\
\hline & Olas & $\begin{array}{l}\text { Flotadres, } \\
\text { columnas, aparatos } \\
\text { focalizadores }\end{array}$ & Electricidad \\
\hline & $\begin{array}{l}\text { Diferencias de } \\
\text { temperaturas }\end{array}$ & $\begin{array}{l}\text { Turbinas } \\
\text { condensadores }\end{array}$ & Electricidad \\
\hline & Corrientes marinas & & Electricidad \\
\hline \multirow{2}{*}{ GEOTERMIA } & Generacion electrica & Plantas de energia & Electricidad \\
\hline & Usos directos & Aguas termales & Calor, recreacion, salud \\
\hline
\end{tabular}

Cuadro tomado de "Energía Alternativa" [ $\left.{ }^{9}\right]$ 
Se pueden destacar las siguientes ventajas de las energías renovables respecto a las energías convencionales:

\begin{tabular}{|c|c|c|}
\hline & E. Renovables & E. Convencionales \\
\hline \multirow{5}{*}{ Diferencias } & Son Limpias & Contaminan \\
\hline & Sin residuos & Generan emisiones y residuos \\
\hline & Inagotables & Son limitadas \\
\hline & Autóctonas & $\begin{array}{l}\text { Provocan dependencia } \\
\text { exterior }\end{array}$ \\
\hline & $\begin{array}{l}\text { Equilibran desajustes } \\
\text { interterritoriales }\end{array}$ & Utilizan tecnología importada \\
\hline \multirow{2}{*}{$\begin{array}{c}\text { Ventajas } \\
\text { medioambientales }\end{array}$} & $\begin{array}{c}\text { Las energías renovables no } \\
\text { producen emisiones de } \mathrm{CO} 2 \text { y } \\
\text { otros gases contaminantes a } \\
\text { la atmosfera. }\end{array}$ & $\begin{array}{l}\text { Las energías producidas a } \\
\text { partir de combustibles fósiles } \\
\text { (petróleo, gas y carbón) si los } \\
\text { producen. }\end{array}$ \\
\hline & $\begin{array}{l}\text { Las energías renovables no } \\
\text { generan residuos de difícil } \\
\text { tratamiento. }\end{array}$ & $\begin{array}{l}\text { La energía nuclear y los } \\
\text { combustibles fósiles generan } \\
\text { residuos que suponen durante } \\
\text { generaciones una amenaza } \\
\text { para el medioambiente. }\end{array}$ \\
\hline \multirow{2}{*}{ Ventajas estratégicas } & $\begin{array}{l}\text { Las energías renovables son } \\
\text { autóctonas. }\end{array}$ & $\begin{array}{l}\text { Los combustibles fósiles } \\
\text { existen sólo en un número } \\
\text { limitado de países. }\end{array}$ \\
\hline & $\begin{array}{c}\text { Las energías renovables } \\
\text { disminuyen la dependencia } \\
\text { exterior }\end{array}$ & $\begin{array}{l}\text { Los combustibles fósiles son } \\
\text { importados en un alto } \\
\text { porcentaje. }\end{array}$ \\
\hline \multirow{3}{*}{$\begin{array}{c}\text { Ventajas } \\
\text { socioeconómicas }\end{array}$} & $\begin{array}{l}\text { Las energías renovables } \\
\text { crean cinco veces más } \\
\text { puestos de trabajo que las } \\
\text { convencionales. }\end{array}$ & $\begin{array}{c}\text { Las energías tradicionales } \\
\text { crean muy pocos puestos de } \\
\text { trabajo respecto a su volumen } \\
\text { de trabajo. }\end{array}$ \\
\hline & $\begin{array}{l}\text { Las energías renovables } \\
\text { contribuyen decisivamente al } \\
\text { equilibrio interterritorial porque } \\
\text { suelen instalarse en zonas } \\
\text { rurales. }\end{array}$ & $\begin{array}{l}\text { Las energías tradicionales se } \\
\text { sitúan en general cerca de } \\
\text { zonas muy desarrolladas. }\end{array}$ \\
\hline & $\begin{array}{l}\text { Las energías renovables han } \\
\text { permitido a España desarrollar } \\
\text { tecnologías propias }\end{array}$ & $\begin{array}{l}\text { Las energías tradicionales } \\
\text { utilizan en su gran mayoría } \\
\text { tecnología importada. }\end{array}$ \\
\hline
\end{tabular}

Cuadro tomado de "INTRODUCCION A LAS ENERGIAS RENOVABLES ${ }^{[9]}$

${ }^{9}$ http://www.agora.ulpgc.es/ficheros/INTRODUCCION_RENOVABLES.pdf 


\section{METODOLGÍA}

La metodología que se llevó a cabo para el desarrollo del proyecto es el siguiente:

$\checkmark$ Población de Muestra: Niños de la Comunidad El Arroyo - Cazucá, ya que el prototipo será colocado en la escuela.

$\checkmark$ Técnica de recolección de datos: en esta etapa del proyecto se observó las diferentes instalaciones que hay en la comunidad El Arroyo, y el parque de juegos, para detallar si se podría usar alguno de estos juegos del parque.

$\checkmark$ Procesamiento de la información: Se hace un análisis de los juegos del parque para decidir si alguno de estos juegos es favorables, pero se opta por hacer el prototipo con una bicicleta estática.

\section{$\checkmark$ Elementos a Utilizar:}

- Bicicleta estática para adulto.

- Plato pedal $16 \mathrm{~cm}$ - Piñón satélite $6 \mathrm{~cm}$ - Rueda o volante de inercia $25 \mathrm{~cm}$.

- Alternador de vehículo 12V - 65A - eje $5 \mathrm{~cm}$.

- Controlador de poder Erasmus

- Batería de ciclo profundo 12V-18Ah-20H.

- Cadena de transmisión.

- Correa de transmisión.

- Cables pasa corriente (AWG 12 y AWG 14)

- Multímetro.

- Lamina en hierro 30×36 cm para acondicionar batería y alternador.

- Cajilla y tapas de protección para elementos eléctricos y mecánicos en movimiento. 
$\checkmark$ Técnicas de análisis: Funcionamiento de un alternador, generación de energía, excitación del alternador, inversor, almacenamiento de energía.

\section{$\checkmark$ Estrategias de Investigación}

a. Documentación.

Se realizó una búsqueda del estado del arte del tema de energías renovables en diferentes bases de datos como lo es la IEEE.

También se utilizó la base de datos EBSCO para búsqueda de información relacionada con investigaciones que ofrezcan como resultado como se almacena la energía.

De igual forma se realiza una consulta en las bibliotecas universitarias y en la red sobre proyectos de grado realizados en la misma temática.

b. Segmentación de la población.

Se escoge una población principalmente de niños de la comunidad El Arroyo entre los 9 y 15 años para hacer las pruebas del prototipo. Además, si algún docente 0 Adulto que forme parte de la Escuela desea hacer uso del prototipo, también lo podrá hacer.

c. Diagrama de bloques del prototipo

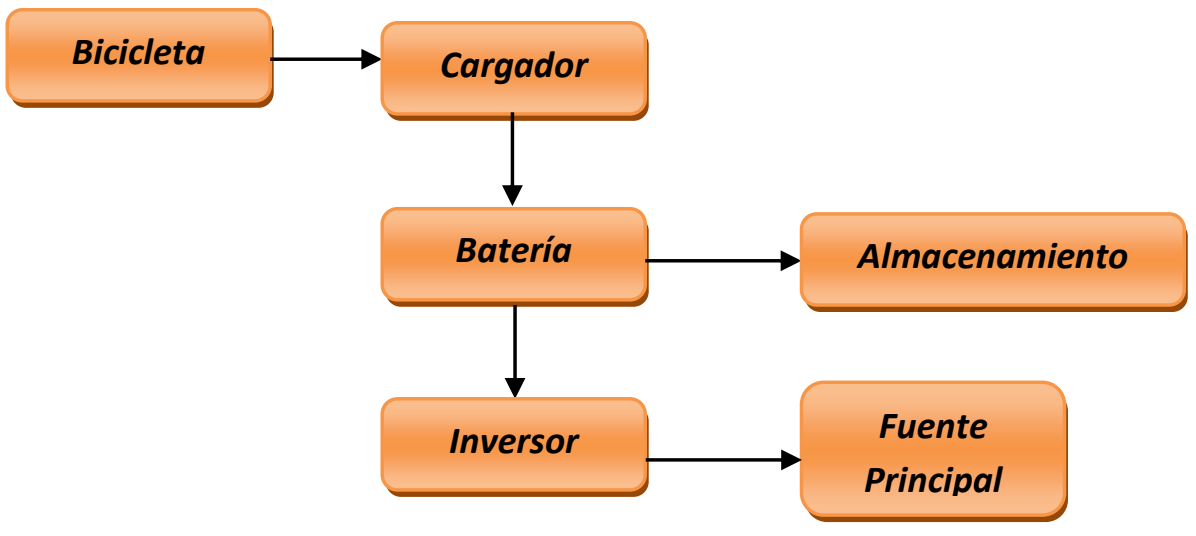




\section{DISEÑO DEL PROTOTIPO}

Se realizó un diseño general de un prototipo que permite almacenar la energía mecánica generada por el pedaleo de una bicicleta estática. Para el diseño de este sistema fue fundamental basarse en la información recolectada, donde se debió tener en cuenta el funcionamiento del alternador y la forma correcta de excitarlo.

\section{Alternador: Esquema conceptual}

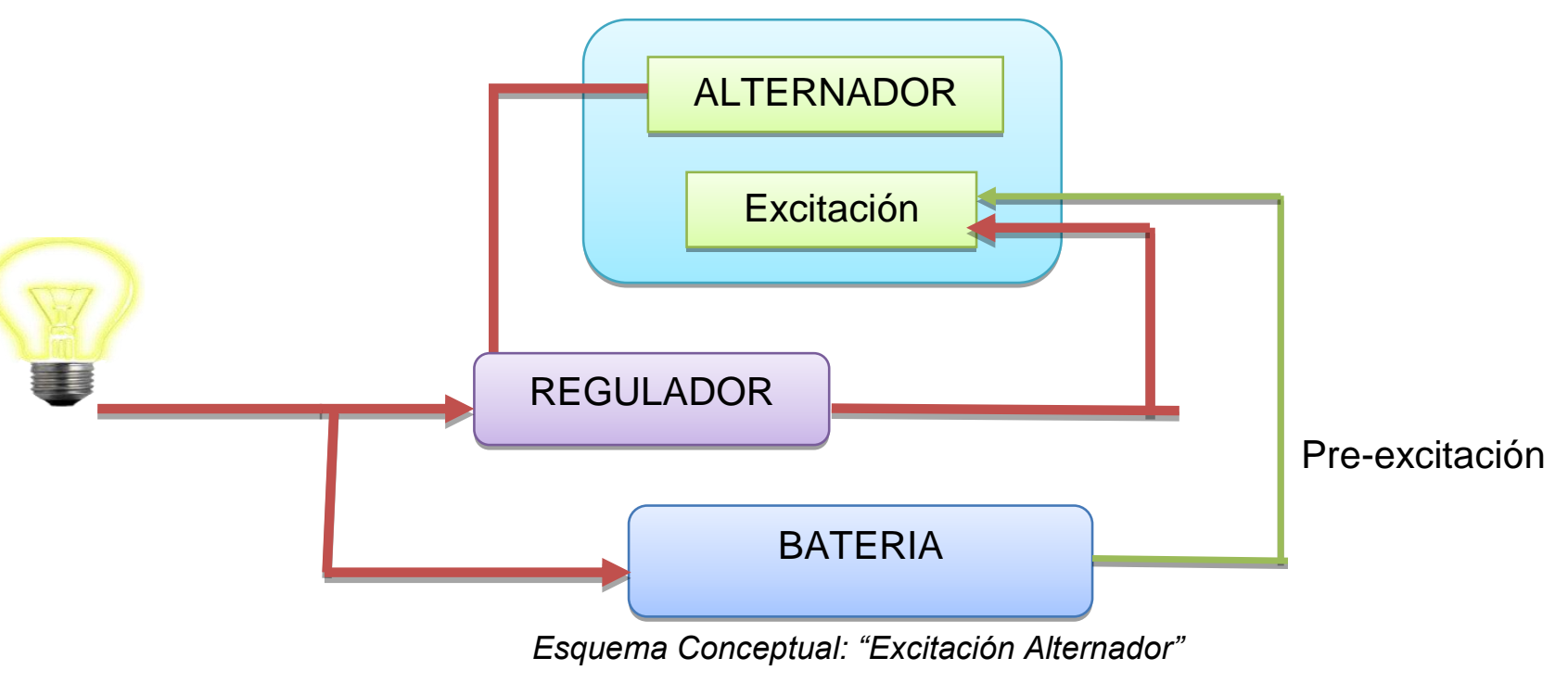

Este esquema representa el funcionamiento conceptual de cómo se comporta el sistema. Para que el alternador comience a generar energía, debe tener una corriente de excitación. Esta corriente de excitación se genera a partir de una corriente de pre-excitación en el alternador, ya que el campo magnético remanente del rotor es muy escaso. Para ello, hay conectado un interruptor de encendido que permite el paso de corriente por la batería, y atraviesa la lámpara de control de carga (luz piloto), el regulador y el devanado de excitación. En el prototipo implementado, se midio que la corriente de pre- excitación variaba entre los $800 \mathrm{~mA}$ y $1 \mathrm{~A}$. 


\section{Descripción general del sistema}

Este sistema se basa en el aprovechamiento de la energía cinética y convertirla en energía eléctrica a partir de un Alternador que nos permitirá generar la corriente necesaria para cargar una batería.

El diseño del sistema de generación de energía consistió en identificar las etapas de generación de la energía y la etapa de gestión de la energía.

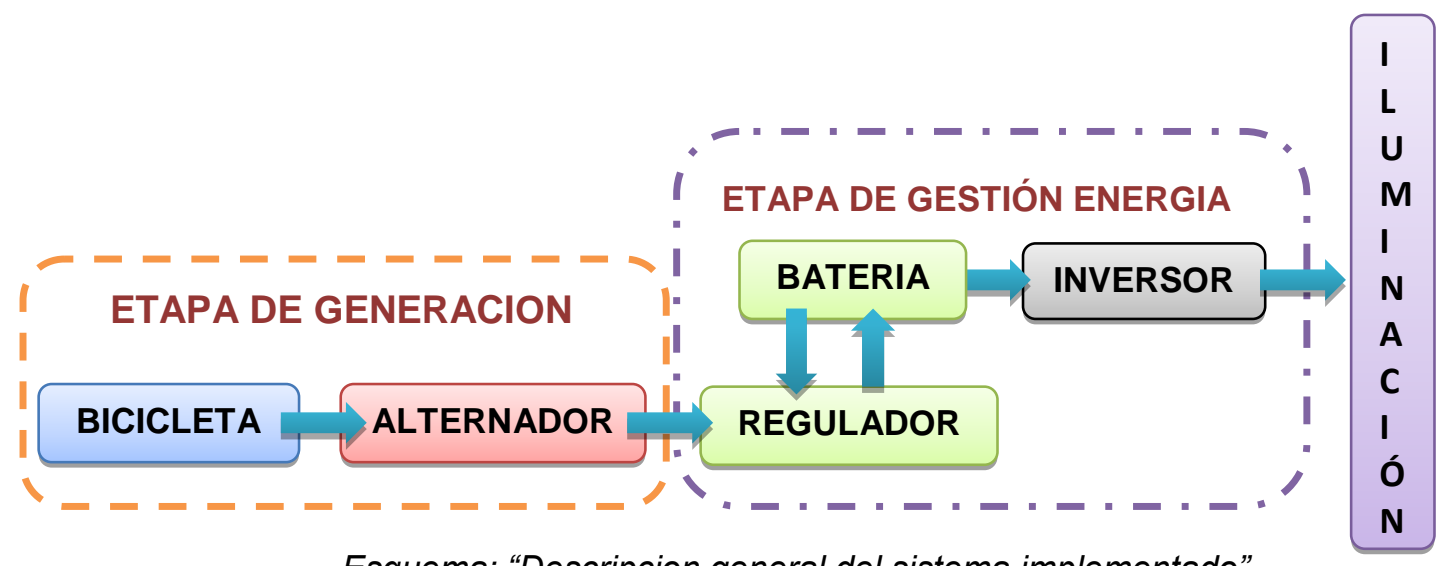

Esquema: "Descripcion general del sistema implementado"

Etapa de generación: En esta etapa, tenemos el funcionamiento mecánico de la bicicleta, el cual requiere un simple impulso en los pedales con las piernas. La bicicleta posee una rueda de inercia o plato a fin de facilitar el pedaleo, que en este sistema a diseñarse, es la parte de contacto por parte del usuario, por la cual se transmitirá la energía de la bicicleta al Alternador.

Etapa de gestión de la energía: En esta etapa la gestión se basa en el almacenamiento y distribución de la energía, la cual obtenemos del alternador que provee un voltaje que es regulado para que la batería pueda almacenar la energía generada por el usuario. La energía almacenada es distribuida por medio de un inversor el cual me permite la conversión en un voltaje simétrico de corriente alterna, que en nuestro caso es a 120VAC y así conectar la carga que puede ser un bombillo. 


\section{Alternador: Esquema de sistema implementado}

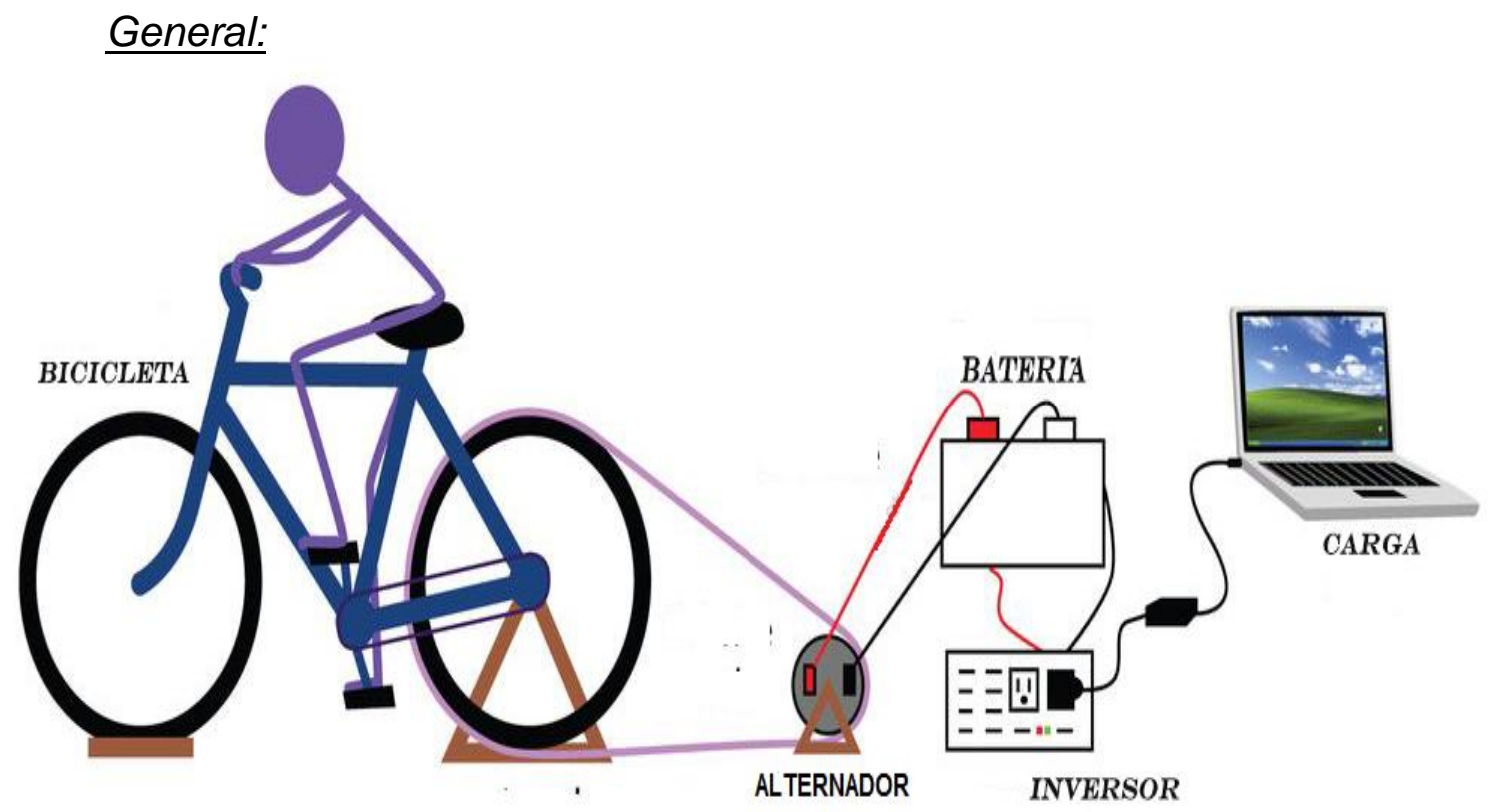

Esquema General del Sistema Implementado tomado de Evolucion Verde [10]

\section{Conexiones:}

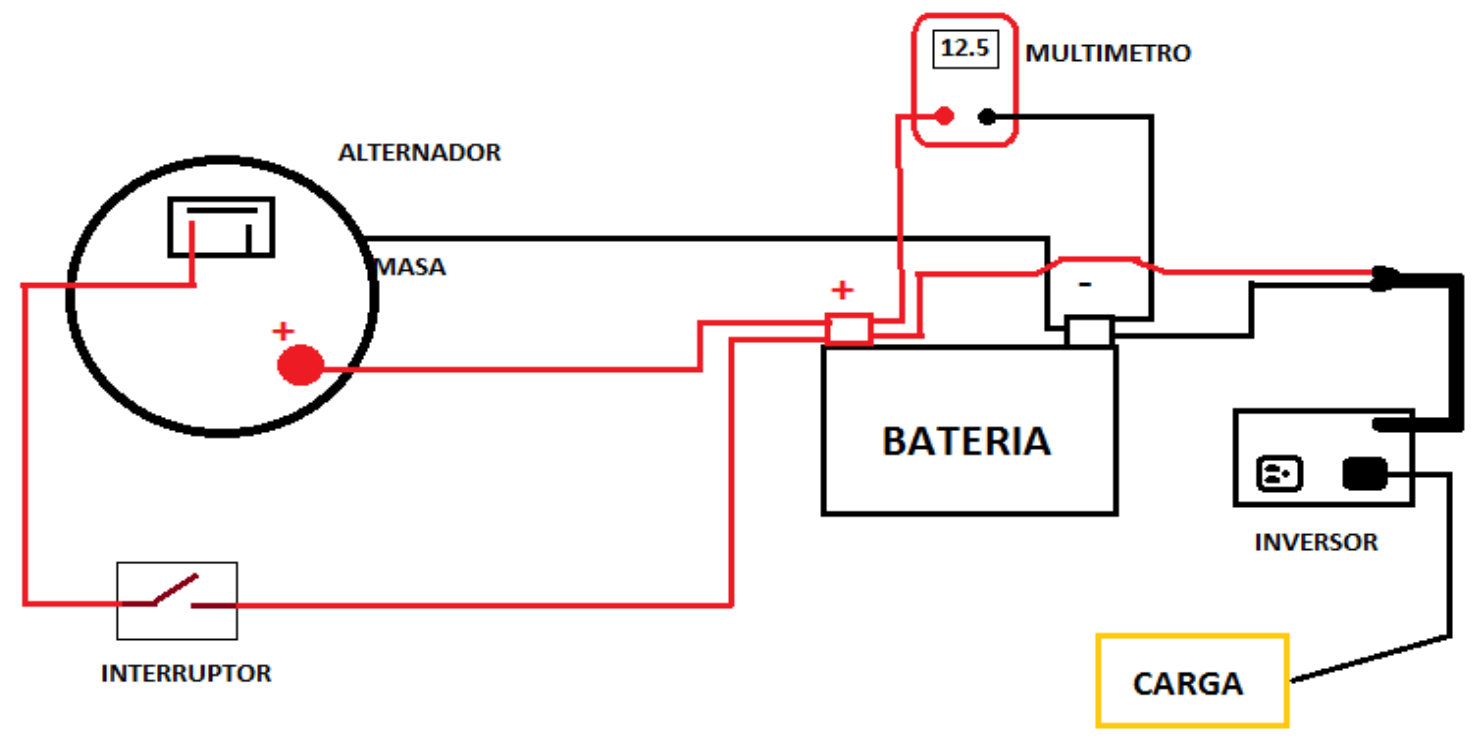

Esquema de las conexciones del sistema implementado, Graficado por Diana Gutierrez

${ }^{10} \mathrm{http}: / /$ evolucionverde.es/bicigeneradores-un-nuevo-horizonte/ 


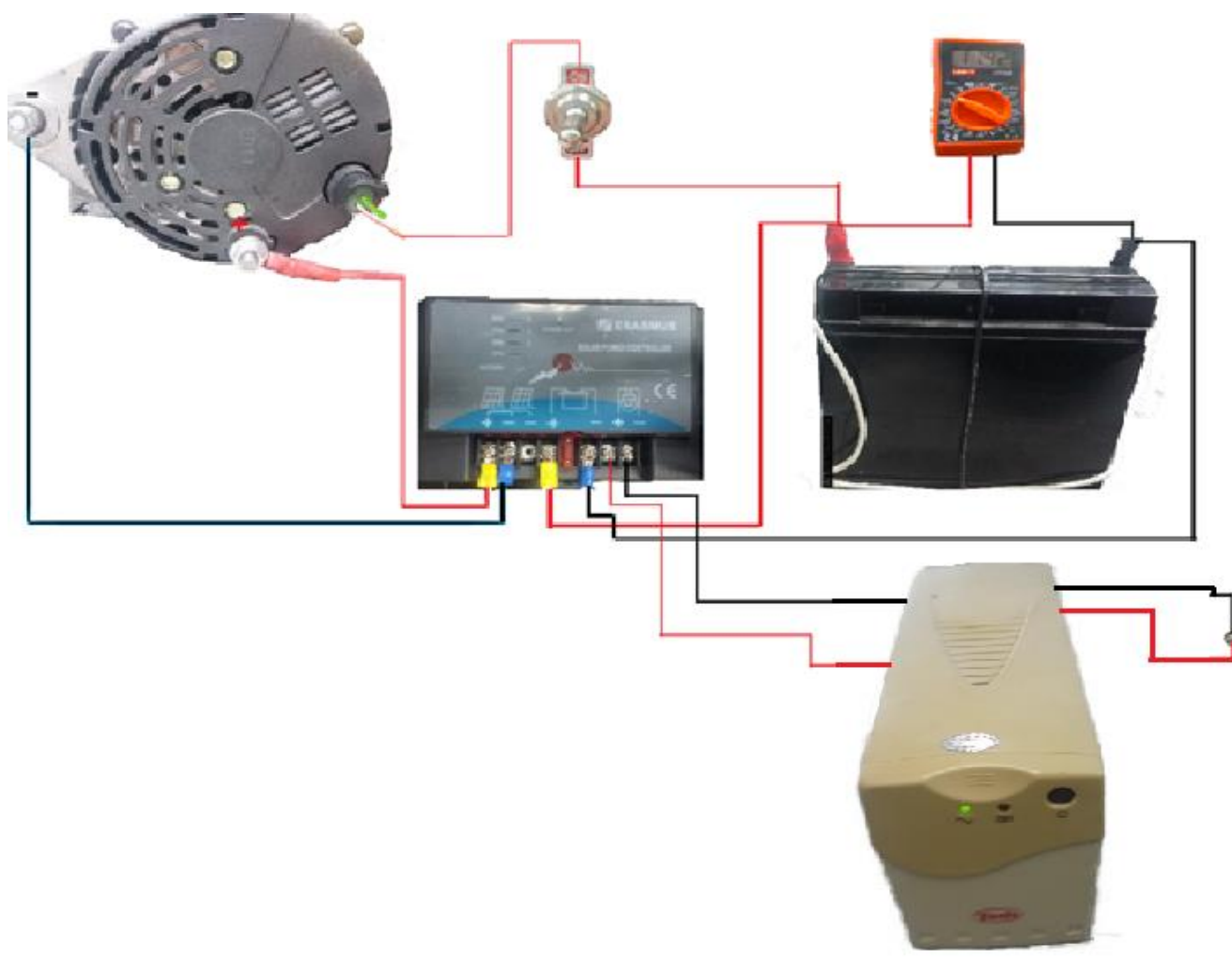

Esquema de las conexciones del sistema implementado con los elementos del prototipo, Graficado por Diana Gutierrez 


\section{CÁLCULOS PARA EL DISEÑO}

\section{REVOLUCIONES POR MINUTO (RPM) EN EL EJE DEL ALTERNADOR}

Como primer paso para dar solución a este proyecto, debemos conocer las revoluciones que generaremos, la cual permitirá al alternador generar energía por medio de una polea. Para ello, utilizaremos la fórmula de relación de transmisión de poleas teniendo en cuenta que este sistema utiliza transmisión de poleas múltiples.

Se conoce que una persona normal a bajo esfuerzo puede hacer girar la rueda de la bicicleta estática a 70 revoluciones por minuto a un ritmo constante y puede hacerla girar a 120 RPM con un esfuerzo alto por un lapso de tiempo relativamente corto, en promedio 5 minutos.

Entonces, tenemos la fórmula:

$$
n_{1} * d_{1}=n_{2} * d_{2}=n_{3} * d_{3}
$$

Dónde: $n=$ revoluciones

$$
d=\text { diametro de las poleas }
$$

Para este diseño del prototipo contamos con los siguientes datos:

$$
\begin{aligned}
& n_{1}=70 \mathrm{rpm}, \quad \text { velocidad de la polea de entrada } \\
& n_{2}=? \\
& n_{3}=? \\
& n_{4}=? \\
& d_{1}=21 \mathrm{~cm} \\
& d_{2}=6 \mathrm{~cm} \\
& d_{3}=30 \mathrm{~cm} \\
& d_{4}=3 \mathrm{~cm}
\end{aligned}
$$




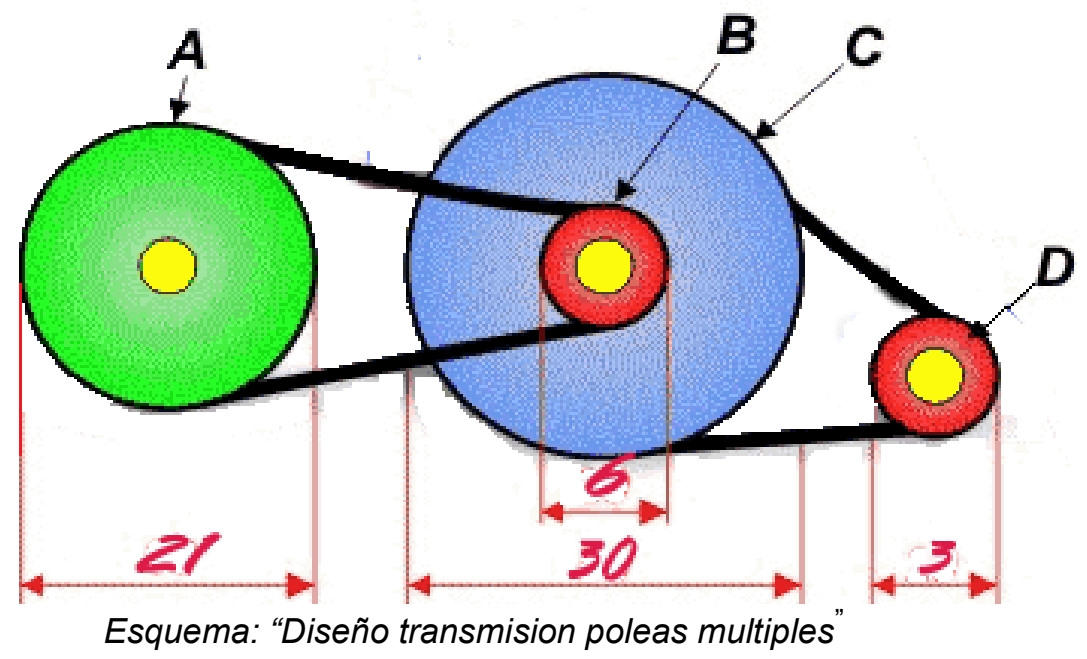

Cálculo de velocidad en el eje 2

$$
\begin{aligned}
& n_{1} * d_{1}=n_{2} * d_{2} \\
& 70 \mathrm{rpm} * 21 \mathrm{~cm}=n_{2} * 6 \mathrm{~cm} \\
& \frac{70 \mathrm{rpm} * 21 \mathrm{~cm}}{6 \mathrm{~cm}}=n_{2} \\
& n_{2}=\frac{1470}{6} \mathrm{rpm} \\
& n_{2}=245 \mathrm{rpm}
\end{aligned}
$$

\section{Cálculo de velocidad en el eje 3}

Hay que tener en cuenta que la velocidad en $n_{2}$ es igual en $n_{3}$, por tanto, decimos que $n_{3}=245 \mathrm{rpm}$

\section{Cálculo de velocidad en el eje 4}

$$
\begin{aligned}
& n_{3} * d_{3}=n_{4} * d_{4} \\
& 245 \mathrm{rpm} * 30 \mathrm{~cm}=n_{4} * 3 \mathrm{~cm} \\
& \frac{245 \mathrm{rpm} * 30 \mathrm{~cm}}{3 \mathrm{~cm}}=n_{4} \\
& n_{4}=\frac{7350}{3} \mathrm{rpm} \\
& n_{4}=2450 \mathrm{rpm}
\end{aligned}
$$


Factor de transmisión en el sistema

$$
\begin{aligned}
& i_{\text {Total }}=\frac{n_{3}}{n_{1}}=\frac{d_{1}}{d_{2}} * \frac{d_{3}}{d_{4}}=\frac{n_{2}}{n_{1}} * \frac{n_{3}}{n_{2}} \\
& i_{\text {Total }}=\frac{245}{70}=\frac{21}{6} * \frac{30}{3}=\frac{245}{70} * \frac{245}{245} \\
& i_{\text {Total }}=3,5=\frac{d_{1}}{d_{2}} * \frac{d_{3}}{d_{4}}=\frac{n_{2}}{n_{1}} * \frac{n_{3}}{n_{2}}
\end{aligned}
$$

Para accionar un alternador y genere energía, como mínimo se deben generar 800 RPM. En este sistema propuesto para una persona normal, sea joven, adulto, hombre o mujer, a partir de un pedaleo normal, se están generando 2450 RPM, valor suficiente para generar la energía necesaria y cargar una batería.

\section{POTENCIA QUE ENTREGA EL ALTERNADOR}

Según la hoja técnica de un alternador para un Chevrolet SPARK obtenemos que:

$$
\begin{gathered}
\text { I_Alternador }=65 \mathrm{Amp} \\
V \_ \text {Alternador }=12 \text { Voltios }
\end{gathered}
$$

Como se conoce, la potencia de un sistema está definida como:

$$
\text { Potencia }=\text { Voltios } * \text { Intensidad }
$$

O también:

Entonces decimos que:

$$
P=V * I
$$

$$
\begin{aligned}
& P=12 v * 65 A \\
& P=780 \text { Watts }
\end{aligned}
$$

En relación al valor calculado, el alternador nos puede entregar esta potencia cuando se encuentre trabajando en un número de revoluciones optimas, que específicamente son 2500 RPM. Cargándose la Batería en un rango de 12.5 voltios a 13.5 voltios. 


\section{POTENCIA PROMEDIO GENERADA POR UNA PERSONA}

La potencia generada por una persona oscila entre 270 Wattios a 400 Wattios, esto se debe a la dinámica del pedaleo que realiza una persona. Teniendo en cuenta la siguiente figura,

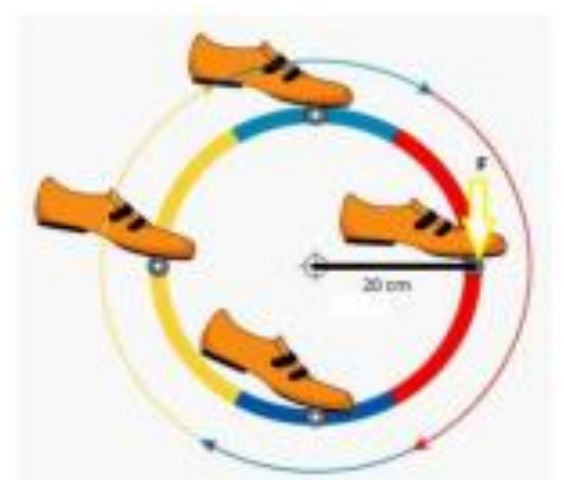

Imagen: "Dinamica del pedaleo que realiza una persona"

Conociendo que el par generado por la fuerza ejercida en el pedaleo está dado por:

$$
T=F \times d
$$

Y conociendo con nuestro prototipo diseñado e implementado que:

$\mathrm{d}=16 \mathrm{~cm}$

Ademas, se conoce que la fuerza promedio que pueden aplicar los adultos, sin distinción de sexo es:

$$
F=294,3 N[7]
$$

Decimos que:

$$
\begin{gathered}
\mathrm{T}=294,3 \mathrm{~N} \times 0,16 \mathrm{~m} \\
\mathrm{~T}=47,088 \mathrm{Nm}
\end{gathered}
$$

Sabemos que para conocer la potencia generada por una persona es:

$$
\mathrm{Pm}=\mathrm{T} \times \omega
$$


Donde $\omega$ es dada en rad/seg y contando que se logra una rps de 6,2832 rad/seg.

$$
\begin{gathered}
\mathrm{Pm}=47,088 \mathrm{Nm} \times 6,2832 \mathrm{rad} / \mathrm{seg} \\
\mathrm{Pm}=295,8633 \text { Watts }
\end{gathered}
$$

Entonces, para este prototipo diseñado la potencia generada por una persona adulta es de aproximadamente 296 Watts.

\section{TIEMPO QUE DEMORA EN CARGAR BATERIA.}

Para calcular teóricamente el tiempo que demorará la batería en cargarse, considerando que no hay pérdidas durante este proceso, no existe ningún dispositivo electrónico conectado y según ciertas características tanto del alternador como de la batería, tenemos:

$$
T c(\text { horas })=\frac{\text { Ah( capacidad de la batería })}{A(\text { capacidad del cargador })}
$$

Si el alternador trabaja a su máxima potencia, tendríamos una capacidad de entrega de $\mathrm{I}=65 \mathrm{~A}$.

En el sistema propuesto, la capacidad de la batería es de 18Ah.

$$
\begin{aligned}
& T c(\text { horas })=\frac{18 A h}{65 A} \\
& T c(\text { horas })=0,2769 \text { horas }
\end{aligned}
$$

La batería tarda un aproximado de 17 minutos en cargarse completamente, considerando que el alternador está trabajando en sus revoluciones óptimas, es decir a 2500RPM. Como ya se ha mencionado anteriormente, para que el alternador se accione y genere energía es necesario generar un mínimo de 800 RPM. Considerando estas mínimas condiciones obtenemos que:

Al Girar el alternador a menos revoluciones, decrece la intensidad de la corriente eléctrica y su rendimiento, por lo tanto entregaría unos 20 Amperios, 
aumentando el tiempo de carga de la batería.

$$
\begin{aligned}
& T c(\text { horas })=\frac{18 A h}{20 A} \\
& T c(\text { horas })=0,9 \text { horas }
\end{aligned}
$$

La batería tardaría un aproximado de 54 minutos en completar la carga con el alternador a 800 RPM. En general podemos decir que para nuestro sistema, la batería se demoraría en cargar entre los 17 minutos y 1 hora. 


\section{PRUEBAS Y CARACTERIZACIÓN.}

Para realizar estas pruebas se tuvo en cuenta jóvenes y adultos entre los 15 y 30 años, de características físicas normales.

Como primera prueba, se les solicitó a estas personas un pedaleo rápido y constante durante 1 minuto, donde se determinó los RPM y el voltaje asociado a la intensidad del pedaleo durante este tiempo.

Como segunda prueba, se les solicito realizar un pedaleo en la bicicleta en un tiempo mayor a 15 minutos hasta donde su resistencia física les permitiera. Para ello se tuvo en cuenta la edad, tiempo de duración, RPM, y el voltaje aumentado en la batería, el cual se obtuvo entre la diferencia del voltaje que registra la batería antes de iniciar el pedaleo con respecto al voltaje al finalizar el pedaleo. Además, se indago un poco acerca de su actividad física, se tuvo en cuenta sus hábitos y entorno donde se desempeñaron las prueba.

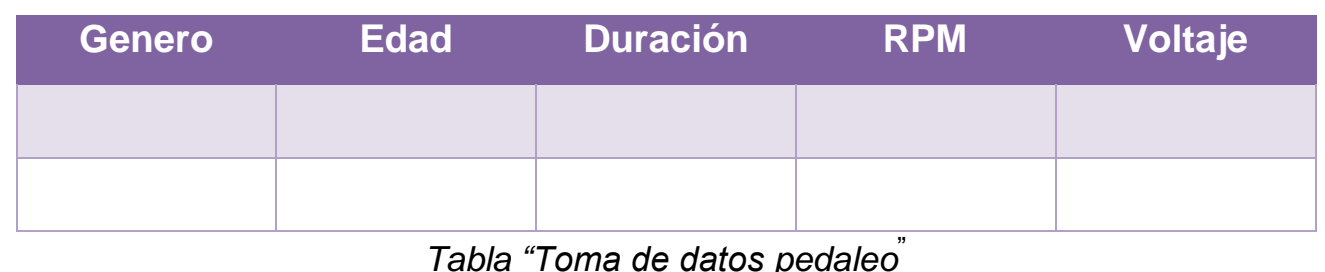

También se realizó pruebas con algunos dispositivos, para determinar el tiempo aproximado que la etapa de almacenamiento de este sistema diseñado puede suministrar. Para ello se tuvo en cuenta el dispositivo o tipo de carga conectado en el inversor y el tiempo aproximado de funcionamiento.

\begin{tabular}{|c|c|c|c|c|c|c|}
\hline Dispositivo & $\begin{array}{l}\text { Tiempo } \\
\text { de Inicio }\end{array}$ & $\begin{array}{l}\text { Voltaje } \\
\text { de Inicio }\end{array}$ & $\begin{array}{l}\text { Tiempo } \\
\text { final }\end{array}$ & $\begin{array}{c}\text { Voltaje } \\
\text { final }\end{array}$ & $\begin{array}{l}\text { Diferencial } \\
\text { de tiempo }\end{array}$ & $\begin{array}{l}\text { Diferencial } \\
\text { de Voltaje }\end{array}$ \\
\hline & & & & & & \\
\hline & & & & & & \\
\hline
\end{tabular}

Tabla "Toma de datos dispositivos" 
Con estas pruebas se establecerán medidas de eficiencia en términos de la energía generada y consumida y se efectuarán comparaciones con otros sistemas energéticos.

Otras pruebas que se tuvieron en cuenta para determinar algunos valores característicos de este sistema fueron la corriente de excitación y la corriente entre el generador y la batería. 


\section{OBTENCIÓN DE RESULTADOS}

\section{Pedaleo durante 1 minuto.}

Para realizar esta prueba se contó con 10 personas entre los 21 y 28 años.

\begin{tabular}{|c|c|c|c|}
\hline Genero & Edad & RPM & voltios \\
\hline Mujer & 26 & 115 & 0.67 \\
\hline Hombre & 28 & 135 & 0.98 \\
\hline Mujer & 22 & 98 & 0.47 \\
\hline Hombre & 21 & 120 & 0.82 \\
\hline Hombre & 25 & 122 & 0.87 \\
\hline Hombre & 24 & 128 & 0.9 \\
\hline Hombre & 22 & 108 & 0.52 \\
\hline Mujer & 24 & 111 & 0.59 \\
\hline Hombre & 27 & 131 & 0.97 \\
\hline Hombre & 23 & 120 & 0.85 \\
\hline
\end{tabular}

Tabla: "Datos de pedaleo por 1 minuto"

\section{Pedaleo durante un tiempo mayor a 15 minutos.}

Para realizar esta prueba se contó con 18 personas entre los 15 y 29 años, se tuvo en cuenta el entorno donde se desempeñó la prueba, y su actividad física, que de acuerdo a la OMS, una persona promedio debe tener actividad física como mínimo 60 minutos para los jóvenes (entre los 5 y 17 años) [11], sin embargo, para los adultos (18 a 64 años) ${ }^{[12]}$ se considera que como mínimo debe hacer 150 minutos semanales, que son aproximadamente 20 minutos diarios.

Partiendo de esto, se decidió consultar con un preparador físico de la Universidad Santo Tomás, quien especifico que para una persona promedio debe realizar como mínimo entre 20 a 30 minutos, para que sea considerado actividad física, sin importar la edad, el entorno, el sexo y la actividad que esté realizando, ya sea caminando, corriendo o pedaleando.

\footnotetext{
${ }^{11} \mathrm{http}: / /$ www.who.int/dietphysicalactivity/factsheet young people/es/

12 http://www.who.int/dietphysicalactivity/factsheet adults/es/
} 
De acuerdo a lo anterior, para determinar la actividad física que desempeño la persona dentro de la prueba, se clasifico de la siguiente manera:

\begin{tabular}{|c|c|c|c|c|}
\hline \multirow{2}{*}{} & \multicolumn{2}{|c|}{ Activas } & \multicolumn{2}{c|}{ Muy Activas } \\
\cline { 2 - 5 } & $\begin{array}{c}\text { Tiempo } \\
\text { (Minutos) }\end{array}$ & $\begin{array}{c}\text { Frecuencia x } \\
\text { semana(dias) }\end{array}$ & $\begin{array}{c}\text { Tiempo } \\
\text { (Minutos) }\end{array}$ & $\begin{array}{c}\text { Frecuencia x } \\
\text { semana(dias) }\end{array}$ \\
\hline Mujer & 20 & 4 & 45 & 7 \\
\hline Hombre & 20 & 4 & 45 & 7 \\
\hline
\end{tabular}

Tabla: "Clasificacion actividad fisica minima"

Las personas que no están dentro de esta clasificación se consideran como sedentaria. Para determinar en qué categoría pertenecen las personas que realizaron la prueba, se indago sobre el tiempo y frecuencia que realizan actividad física.

Adicional, se tomó las RPM de las personas al pedalear cada 5 minutos, esto para determinar un promedio de sus RPM, ya que su pedaleo no siempre fue constante. 


\begin{tabular}{|c|c|c|c|c|c|c|c|c|c|c|c|c|c|c|c|c|}
\hline \multirow[b]{2}{*}{ Genero } & \multirow[b]{2}{*}{ Edad } & \multirow[b]{2}{*}{ Duración } & \multicolumn{10}{|c|}{ RPM } & \multirow{2}{*}{$\begin{array}{l}\text { Promedio } \\
\text { RPM }\end{array}$} & \multirow{2}{*}{$\begin{array}{l}\text { Actividad } \\
\text { Física }\end{array}$} & \multirow{2}{*}{$\begin{array}{l}\text { Voltaje } \\
\text { Final } \\
\text { Batería }\end{array}$} & \multirow{2}{*}{$\begin{array}{l}\text { Voltaje } \\
\text { efectivo }\end{array}$} \\
\hline & & & $\begin{array}{c}5 \\
\mathrm{~min}\end{array}$ & $\begin{array}{c}10 \\
\min \end{array}$ & $\begin{array}{c}15 \\
\mathrm{~min}\end{array}$ & $\begin{array}{c}20 \\
\mathrm{~min}\end{array}$ & $\begin{array}{l}25 \\
\mathrm{~min}\end{array}$ & $\begin{array}{c}30 \\
\mathrm{~min}\end{array}$ & $\begin{array}{c}35 \\
\mathrm{~min}\end{array}$ & $\begin{array}{l}40 \\
\mathrm{~min}\end{array}$ & $\begin{array}{c}45 \\
\mathrm{~min}\end{array}$ & $\begin{array}{l}50 \\
\mathrm{~min}\end{array}$ & & & & \\
\hline Hombre & $\begin{array}{c}15 \\
\text { años }\end{array}$ & $\begin{array}{c}17 \\
\text { minutos }\end{array}$ & 110 & 100 & 113 & & & & & & & & 107,67 & Activo & 13,30 & 12,73 \\
\hline Hombre & $\begin{array}{c}15 \\
\text { años }\end{array}$ & $\begin{array}{c}20 \\
\text { minutos }\end{array}$ & 115 & 108 & 106 & 110 & & & & & & & 109,75 & Activo & 12,90 & 12,32 \\
\hline Mujer & $\begin{array}{c}26 \\
\text { años }\end{array}$ & $\begin{array}{c}20 \\
\text { minutos }\end{array}$ & 114 & 96 & 95 & 106 & & & & & & & 102,75 & sedentario & 12,50 & 12,00 \\
\hline Hombre & $\begin{array}{c}28 \\
\text { años }\end{array}$ & $\begin{array}{c}40 \\
\text { minutos }\end{array}$ & 130 & 128 & 131 & 130 & 119 & 125 & 127 & 125 & & & 126,88 & Muy Activo & 14,50 & 13,66 \\
\hline Mujer & $\begin{array}{c}22 \\
\text { años }\end{array}$ & $\begin{array}{c}28 \\
\text { minutos }\end{array}$ & 105 & 108 & 102 & 97 & 99 & & & & & & 102,20 & Sedentario & 11,80 & 11,42 \\
\hline Hombre & $\begin{array}{c}21 \\
\text { años }\end{array}$ & $\begin{array}{c}36 \\
\text { minutos }\end{array}$ & 120 & 114 & 112 & 115 & 109 & 110 & 120 & & & & 114,29 & Sedentario & 12,80 & 12,00 \\
\hline Hombre & $\begin{array}{c}25 \\
\text { años }\end{array}$ & $\begin{array}{c}40 \\
\text { minutos }\end{array}$ & 128 & 127 & 123 & 119 & 120 & 119 & 118 & 120 & & & 121,75 & Muy Activo & 13,80 & 13,11 \\
\hline Hombre & $\begin{array}{c}24 \\
\text { años }\end{array}$ & $\begin{array}{c}35 \\
\text { minutos }\end{array}$ & 122 & 125 & 124 & 120 & 121 & 118 & 115 & & & & 120,71 & Activo & 13,50 & 12,99 \\
\hline Hombre & $\begin{array}{c}22 \\
\text { años }\end{array}$ & $\begin{array}{c}48 \\
\text { minutos }\end{array}$ & 120 & 123 & 121 & 120 & 123 & 122 & 117 & 118 & 120 & & 120,44 & Muy Activo & 13,70 & 12,98 \\
\hline Mujer & $\begin{array}{c}24 \\
\text { años }\end{array}$ & $\begin{array}{c}25 \\
\text { minutos }\end{array}$ & 109 & 110 & 105 & 99 & 100 & & & & & & 104,60 & Activo & 13,00 & 12,28 \\
\hline Hombre & $\begin{array}{c}29 \\
\text { años }\end{array}$ & $\begin{array}{c}48 \\
\text { minutos }\end{array}$ & 121 & 118 & 117 & 115 & 120 & 119 & 116 & 122 & 120 & & 118,67 & Activo & 14,20 & 13,57 \\
\hline
\end{tabular}




\begin{tabular}{|c|c|c|c|c|c|c|c|c|c|c|c|c|c|c|c|c|}
\hline Mujer & $\begin{array}{c}21 \\
\text { años }\end{array}$ & $\begin{array}{c}25 \\
\text { minutos }\end{array}$ & 102 & 100 & 97 & 92 & 90 & & & & & & 96,20 & Activo & 13,80 & 13,08 \\
\hline Hombre & $\begin{array}{c}23 \\
\text { años }\end{array}$ & $\begin{array}{c}30 \\
\text { minutos }\end{array}$ & 110 & 105 & 103 & 102 & 103 & 105 & & & & & 104,67 & Activo & 13,30 & 12,61 \\
\hline Hombre & $\begin{array}{c}25 \\
\text { años }\end{array}$ & $\begin{array}{c}38 \\
\text { minutos }\end{array}$ & 98 & 104 & 100 & 97 & 108 & 112 & 109 & & & & 104,00 & Activo & 14,05 & 13,28 \\
\hline Mujer & $\begin{array}{c}22 \\
\text { años }\end{array}$ & $\begin{array}{c}27 \\
\text { minutos }\end{array}$ & 111 & 113 & 110 & 107 & 105 & & & & & & 109,20 & Activo & 13,60 & 12,81 \\
\hline Hombre & $\begin{array}{c}27 \\
\text { años }\end{array}$ & $\begin{array}{c}50 \\
\text { minutos }\end{array}$ & 106 & 105 & 100 & 107 & 103 & 101 & 108 & 111 & 109 & 103 & 105,30 & Muy Activo & 13,10 & 11,87 \\
\hline Mujer & $\begin{array}{c}22 \\
\text { años }\end{array}$ & $\begin{array}{c}20 \\
\text { minutos }\end{array}$ & 98 & 95 & 92 & 90 & & & & & & & 93,75 & sedentario & 11,70 & 11,00 \\
\hline Hombre & $\begin{array}{c}23 \\
\text { años }\end{array}$ & $\begin{array}{c}42 \\
\text { minutos }\end{array}$ & 108 & 110 & 115 & 109 & 103 & 110 & 109 & 111 & & & 109,38 & Activo & 13,80 & 13,28 \\
\hline
\end{tabular}

Tabla: "Datos de pedaleo durante tiempo mayor a 15 minutos" 
Tiempo de duración de la batería con diferentes dispositivos.

\begin{tabular}{|c|c|c|c|c|c|c|c|}
\hline Dispositivo & $\begin{array}{l}\text { Tiempo } \\
\text { de Inicio }\end{array}$ & $\begin{array}{l}\text { Voltaj } \\
\text { e de } \\
\text { Inicio }\end{array}$ & $\begin{array}{l}\text { Tiempo } \\
\text { final }\end{array}$ & $\begin{array}{l}\text { Voltaje } \\
\text { final }\end{array}$ & $\begin{array}{l}\text { Diferencial } \\
\text { de tiempo }\end{array}$ & $\begin{array}{l}\text { Diferencial } \\
\text { de Voltaje }\end{array}$ & Novedades \\
\hline $\begin{array}{c}\text { Bombillo } \\
15 \mathrm{~W}\end{array}$ & $\begin{array}{c}\text { 03:32 p. } \\
\text { m. }\end{array}$ & 12,33 & $\begin{array}{l}09: 30 \\
\text { p. m. }\end{array}$ & 10,2 & $05: 58$ & 2,13 & $\begin{array}{c}\text { Descarga } \\
\text { completa de } \\
\text { batería }\end{array}$ \\
\hline $\begin{array}{l}\text { Bombillo } \\
110 \mathrm{~W}\end{array}$ & $\begin{array}{c}\text { 03:00 p. } \\
\text { m. }\end{array}$ & 12,28 & $\begin{array}{l}\text { 05:00 } \\
\text { p. m. }\end{array}$ & 10,1 & 02:00 & 2,18 & $\begin{array}{c}\text { Descarga } \\
\text { completa de } \\
\text { batería }\end{array}$ \\
\hline $\begin{array}{l}\text { Celular } \\
\text { (Batería } \\
1,85 W h)\end{array}$ & $\begin{array}{c}\text { 03:40 p. } \\
\text { m. }\end{array}$ & 12,53 & $\begin{array}{l}05: 42 \\
\text { p. m. }\end{array}$ & 12,49 & 02:02 & 0,04 & $\begin{array}{c}\text { Descarga } \\
\text { parcial de la } \\
\text { batería }\end{array}$ \\
\hline MP3 & $\begin{array}{c}\text { 05:30 p. } \\
\text { m. }\end{array}$ & 11,7 & $22: 00$ & 11,1 & 04:30 & 0,6 & $\begin{array}{c}\text { Descarga } \\
\text { parcial de la } \\
\text { batería }\end{array}$ \\
\hline
\end{tabular}

Tabla: "Tiempo funcionamiento con dispositivos" 


\section{ANÁLISIS DE LOS RESULTADOS}

\section{Pedaleo durante 1 minuto.}

De acuerdo a las pruebas realizadas, tomamos estos valores y se organiza las RPM de menor a mayor y efectuamos la gráfica.

\begin{tabular}{|c|c|c|c|}
\hline Genero & Edad & RPM & voltios \\
\hline Mujer & 22 & 98 & 0,47 \\
\hline Hombre & 22 & 108 & 0,52 \\
\hline Mujer & 24 & 111 & 0,59 \\
\hline Mujer & 26 & 115 & 0,67 \\
\hline Hombre & 21 & 120 & 0,82 \\
\hline Hombre & 23 & 120 & 0,85 \\
\hline Hombre & 25 & 122 & 0,87 \\
\hline Hombre & 24 & 128 & 0,9 \\
\hline Hombre & 27 & 131 & 0,97 \\
\hline Hombre & 28 & 135 & 0,98 \\
\hline
\end{tabular}

Tabla : "Datos de pedaleo por 1 minuto"

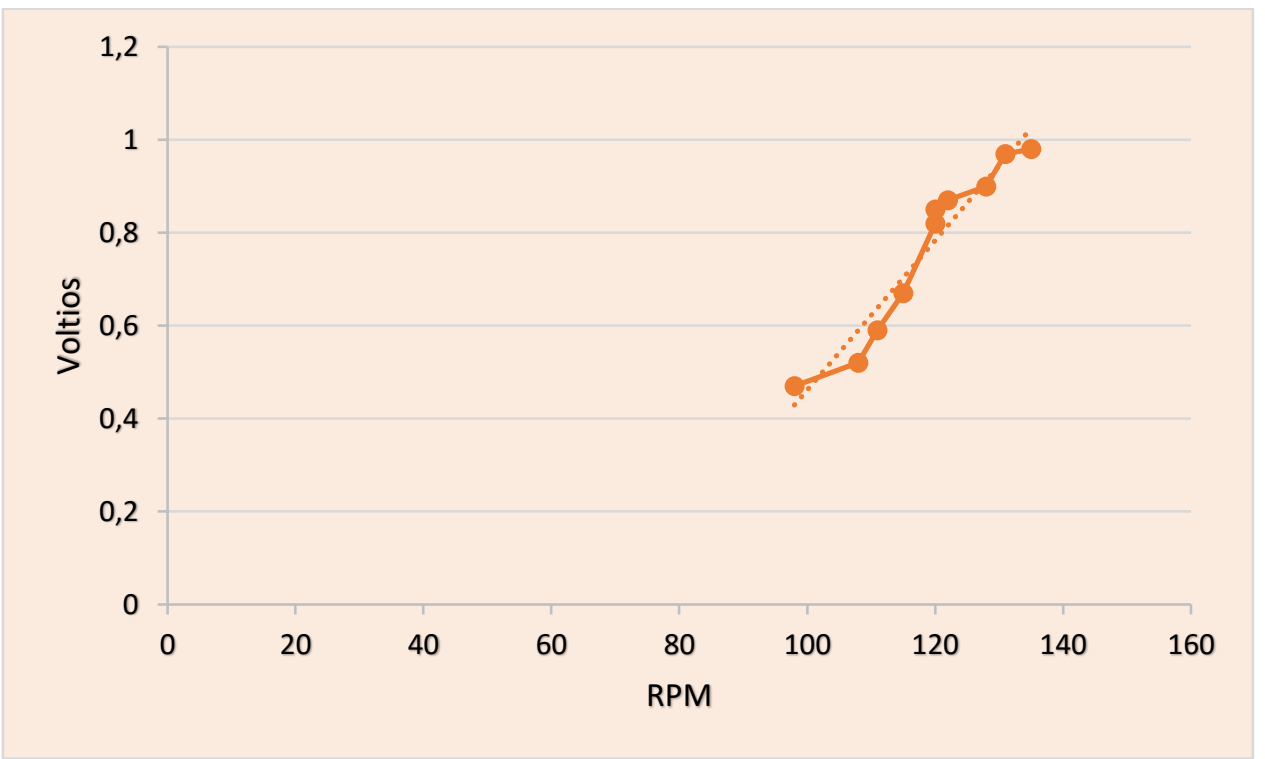

A partir de la gráfica, se puede observar que las revoluciones son directamente proporcionales al voltaje generado, donde la RPM promedio general es de 118,8 RPM, 123,4 RPM para los hombres y 108 RPM para las mujeres. 
Además, se observa que a partir de las 120 RPM, se está generando aproximadamente 1 voltio, esto a pedaleo casi constante.

\section{> Pedaleo durante un tiempo mayor a 15 minutos.}

Para efectuar un análisis simplificamos un poco la tabla con toda la información anteriormente presentada, donde excluimos las RPM tomadas cada 5 minutos y el entorno en el que se desempeñaron, ya que de acuerdo con el preparador físico, el entorno en el que se desarrolla la actividad física no influye en la misma.

Teniendo en cuenta la corriente que transita entre el alternador y la batería, de 2,2 Amperios, podemos determinar la potencia promedio que está generando la persona al pedalear.

\begin{tabular}{|c|c|c|c|c|c|c|}
\hline Genero & Edad & Duración & $\begin{array}{c}\text { Promedio } \\
\text { RPM }\end{array}$ & $\begin{array}{c}\text { Actividad } \\
\text { Física }\end{array}$ & $\begin{array}{c}\text { Voltaje } \\
\text { efectivo }\end{array}$ & $\begin{array}{c}\text { Potencia } \\
\text { Generada }\end{array}$ \\
\hline Hombre & $\begin{array}{c}15 \\
\text { años }\end{array}$ & $\begin{array}{c}17 \\
\text { minutos }\end{array}$ & 107,67 & Activo & 12,43 & 27,35 \\
\hline Hombre & $\begin{array}{c}15 \\
\text { años }\end{array}$ & $\begin{array}{c}20 \\
\text { minutos }\end{array}$ & 109,75 & Activo & 11,72 & 25,78 \\
\hline Mujer & $\begin{array}{c}26 \\
\text { años }\end{array}$ & $\begin{array}{c}20 \\
\text { minutos }\end{array}$ & 102,75 & sedentario & 11,80 & 25,96 \\
\hline Hombre & $\begin{array}{c}28 \\
\text { años }\end{array}$ & $\begin{array}{c}40 \\
\text { minutos }\end{array}$ & 126,88 & Muy Activo & 13,66 & 30,05 \\
\hline Mujer & $\begin{array}{c}22 \\
\text { años }\end{array}$ & $\begin{array}{c}28 \\
\text { minutos }\end{array}$ & 102,20 & Sedentario & 11,42 & 25,12 \\
\hline Hombre & $\begin{array}{c}21 \\
\text { años }\end{array}$ & $\begin{array}{c}36 \\
\text { minutos }\end{array}$ & 114,29 & Sedentario & 12,00 & 26,40 \\
\hline Hombre & $\begin{array}{c}25 \\
\text { años }\end{array}$ & $\begin{array}{c}40 \\
\text { minutos }\end{array}$ & 121,75 & Muy Activo & 13,11 & 28,84 \\
\hline Hombre & $\begin{array}{c}24 \\
\text { años }\end{array}$ & $\begin{array}{c}35 \\
\text { minutos }\end{array}$ & 120,71 & Activo & 12,99 & 28,58 \\
\hline Hombre & $\begin{array}{c}22 \\
\text { años }\end{array}$ & $\begin{array}{c}48 \\
\text { minutos }\end{array}$ & 120,44 & Muy Activo & 12,98 & 28,56 \\
\hline Mujer & $\begin{array}{c}24 \\
\text { años }\end{array}$ & $\begin{array}{c}25 \\
\text { minutos }\end{array}$ & 104,60 & Activo & 12,28 & 27,02 \\
\hline Hombre & $\begin{array}{c}29 \\
\text { años }\end{array}$ & $\begin{array}{c}48 \\
\text { minutos }\end{array}$ & 118,67 & Activo & 13,57 & 29,85 \\
\hline
\end{tabular}




\begin{tabular}{|c|c|c|c|c|c|c|}
\hline Mujer & $\begin{array}{c}21 \\
\text { años }\end{array}$ & $\begin{array}{c}25 \\
\text { minutos }\end{array}$ & 96,20 & Activo & 13,08 & 28,78 \\
\hline Hombre & $\begin{array}{c}23 \\
\text { años }\end{array}$ & $\begin{array}{c}30 \\
\text { minutos }\end{array}$ & 104,67 & Activo & 12,61 & 27,74 \\
\hline Hombre & $\begin{array}{c}25 \\
\text { años }\end{array}$ & $\begin{array}{c}38 \\
\text { minutos }\end{array}$ & 104,00 & Activo & 13,28 & 29,22 \\
\hline Mujer & $\begin{array}{c}22 \\
\text { años }\end{array}$ & $\begin{array}{c}27 \\
\text { minutos }\end{array}$ & 109,20 & Activo & 12,81 & 28,18 \\
\hline Hombre & $\begin{array}{c}27 \\
\text { años }\end{array}$ & $\begin{array}{c}50 \\
\text { minutos }\end{array}$ & 105,30 & Muy Activo & 11,87 & 26,11 \\
\hline Mujer & $\begin{array}{c}22 \\
\text { años }\end{array}$ & $\begin{array}{c}20 \\
\text { minutos }\end{array}$ & 93,75 & sedentario & 11,00 & 24,20 \\
\hline Hombre & $\begin{array}{c}23 \\
\text { años }\end{array}$ & $\begin{array}{c}42 \\
\text { minutos }\end{array}$ & 109,38 & Activo & 13,28 & 29,22 \\
\hline
\end{tabular}

Tabla: "Datos de pedaleo durante tiempo mayor a 15 minutos simplificada"

Para efectuar el análisis se tuvo en cuenta las 3 clasificaciones de acuerdo a la actividad que realizaban cada una de las personas durante una semana, especificada en la tabla: "Clasificación actividad física mínima".

\begin{tabular}{|c|c|c|c|c|c|}
\hline \multicolumn{6}{|c|}{ ACTIVIDAD FISICA SEDENTARIA } \\
\hline Genero Edad & Duración & $\begin{array}{c}\text { Promedio } \\
\text { RPM }\end{array}$ & $\begin{array}{c}\text { Voltaje } \\
\text { carga } \\
\text { Batería }\end{array}$ & $\begin{array}{c}\text { Voltaje } \\
\text { Efectivo }\end{array}$ \\
\hline Mujer & $\begin{array}{c}26 \\
\text { años }\end{array}$ & $\begin{array}{c}20 \\
\text { minutos }\end{array}$ & 102,75 & 12,3 & 11,8 \\
\hline Mujer & $\begin{array}{c}22 \\
\text { años }\end{array}$ & $\begin{array}{c}28 \\
\text { minutos }\end{array}$ & 102,20 & 11,8 & 11,42 \\
\hline Hombre & $\begin{array}{c}21 \\
\text { años }\end{array}$ & $\begin{array}{c}36 \\
\text { minutos }\end{array}$ & 117,29 & 12,8 & 12 \\
\hline Mujer & $\begin{array}{c}22 \\
\text { años }\end{array}$ & $\begin{array}{c}20 \\
\text { minutos }\end{array}$ & 93,75 & 11,7 & 11 \\
\hline
\end{tabular}

Tabla : "Datos de pedaleo por categoria sedentaria"

Dentro de esta categorización evaluamos como una persona con poca actividad física, puede generar entre los 1.50 voltios hasta los 2.7 voltios como carga efectiva. 


\begin{tabular}{|c|c|c|c|c|c|}
\hline \multicolumn{6}{|c|}{ ACTIVIDAD FISICA ACTIVA } \\
\hline Genero & Edad & Duración & $\begin{array}{c}\text { Promedio } \\
\text { RPM }\end{array}$ & $\begin{array}{c}\text { Voltaje } \\
\text { carga } \\
\text { Batería }\end{array}$ & $\begin{array}{c}\text { Voltaje } \\
\text { Efectivo }\end{array}$ \\
\hline Hombre & $\begin{array}{c}15 \\
\text { años }\end{array}$ & $\begin{array}{c}17 \\
\text { minutos }\end{array}$ & 107,67 & 13 & 12,43 \\
\hline Hombre & $\begin{array}{c}15 \\
\text { años }\end{array}$ & $\begin{array}{c}20 \\
\text { minutos }\end{array}$ & 109,75 & 12,3 & 11,72 \\
\hline Hombre & $\begin{array}{c}24 \\
\text { años }\end{array}$ & $\begin{array}{c}35 \\
\text { minutos }\end{array}$ & 120,71 & 13,50 & 12,99 \\
\hline Mujer & $\begin{array}{c}24 \\
\text { años }\end{array}$ & $\begin{array}{c}25 \\
\text { minutos }\end{array}$ & 104,60 & 13 & 12,28 \\
\hline Hombre & $\begin{array}{c}29 \\
\text { años }\end{array}$ & $\begin{array}{c}48 \\
\text { minutos }\end{array}$ & 118,67 & 14,20 & 13,57 \\
\hline Mujer & $\begin{array}{c}21 \\
\text { años }\end{array}$ & $\begin{array}{c}25 \\
\text { minutos }\end{array}$ & 96,20 & 13,80 & 13,08 \\
\hline Hombre & $\begin{array}{c}23 \\
\text { años }\end{array}$ & $\begin{array}{c}30 \\
\text { minutos }\end{array}$ & 104,67 & 13,30 & 12,61 \\
\hline Hombre & $\begin{array}{c}25 \\
\text { años }\end{array}$ & $\begin{array}{c}38 \\
\text { minutos }\end{array}$ & 104,00 & 14,05 & 13,28 \\
\hline Mujer & $\begin{array}{c}22 \\
\text { años }\end{array}$ & $\begin{array}{c}27 \\
\text { minutos }\end{array}$ & 109,20 & 13,60 & 12,81 \\
\hline Hombre & $\begin{array}{c}23 \\
\text { años }\end{array}$ & $\begin{array}{c}42 \\
\text { minutos }\end{array}$ & 109,38 & 13,8 & 13,28 \\
\hline
\end{tabular}

Tabla : "Datos de pedaleo por categoria Activa"

Dentro de esta categorización evaluamos como una persona con poca actividad física, puede generar entre los 1.98 voltios hasta los 3.61 voltios como carga efectiva.

\begin{tabular}{|c|c|c|c|c|c|}
\hline \multicolumn{6}{|c|}{ ACTIVIDAD FISICA MUY ACTIVA } \\
Genero & Edad & Duración & $\begin{array}{c}\text { Promedio } \\
\text { RPM }\end{array}$ & $\begin{array}{c}\text { Voltaje } \\
\text { carga } \\
\text { Batería }\end{array}$ & $\begin{array}{c}\text { Voltaje } \\
\text { Efectivo }\end{array}$ \\
\hline Hombre & $\begin{array}{c}28 \\
\text { años }\end{array}$ & $\begin{array}{c}40 \\
\text { minutos }\end{array}$ & 126,88 & 14,50 & 13,66 \\
\hline Hombre & $\begin{array}{c}25 \\
\text { años }\end{array}$ & $\begin{array}{c}40 \\
\text { minutos }\end{array}$ & 121,75 & 13,80 & 13,11 \\
\hline Hombre & $\begin{array}{c}22 \\
\text { años }\end{array}$ & $\begin{array}{c}48 \\
\text { minutos }\end{array}$ & 120,44 & 13,70 & 12,98 \\
\hline Hombre & $\begin{array}{c}27 \\
\text { años }\end{array}$ & $\begin{array}{c}50 \\
\text { minutos }\end{array}$ & 105,30 & 13,10 & 11,87 \\
\hline
\end{tabular}

Tabla : "Datos de pedaleo por categoria muy activa" 
Dentro de esta categorización evaluamos como una persona con poca actividad física, puede generar entre los 2.67 voltios hasta los 3.84 voltios como carga efectiva.

Reducimos toda esta información en una sola tabla.

\begin{tabular}{|c|c|c|c|}
\hline \multirow{2}{*}{$\begin{array}{c}\text { Actividad } \\
\text { Física }\end{array}$} & \multicolumn{2}{|c|}{$\begin{array}{c}\text { RPM } \\
\text { PROMEDIO }\end{array}$} & \multirow{2}{*}{$\begin{array}{c}\text { Voltaje } \\
\text { efectivo }\end{array}$} \\
\cline { 2 - 3 } & Mujer & Hombre & \\
\hline Sedentario & 99,57 & 114,29 & $11-12$ \\
\hline Activo & 103,33 & 110,69 & $11,72-13,57$ \\
\hline Muy Activo & N/A & 118,59 & $11,87-13,66$ \\
\hline
\end{tabular}

Tabla : "Cuadro de categorización por actividad fisica del individuo"

En la tabla anterior obtenemos una caracterización con respecto a la actividad física del individuo, permitiéndonos evaluar el comportamiento que tiene el prototipo según su categorización.

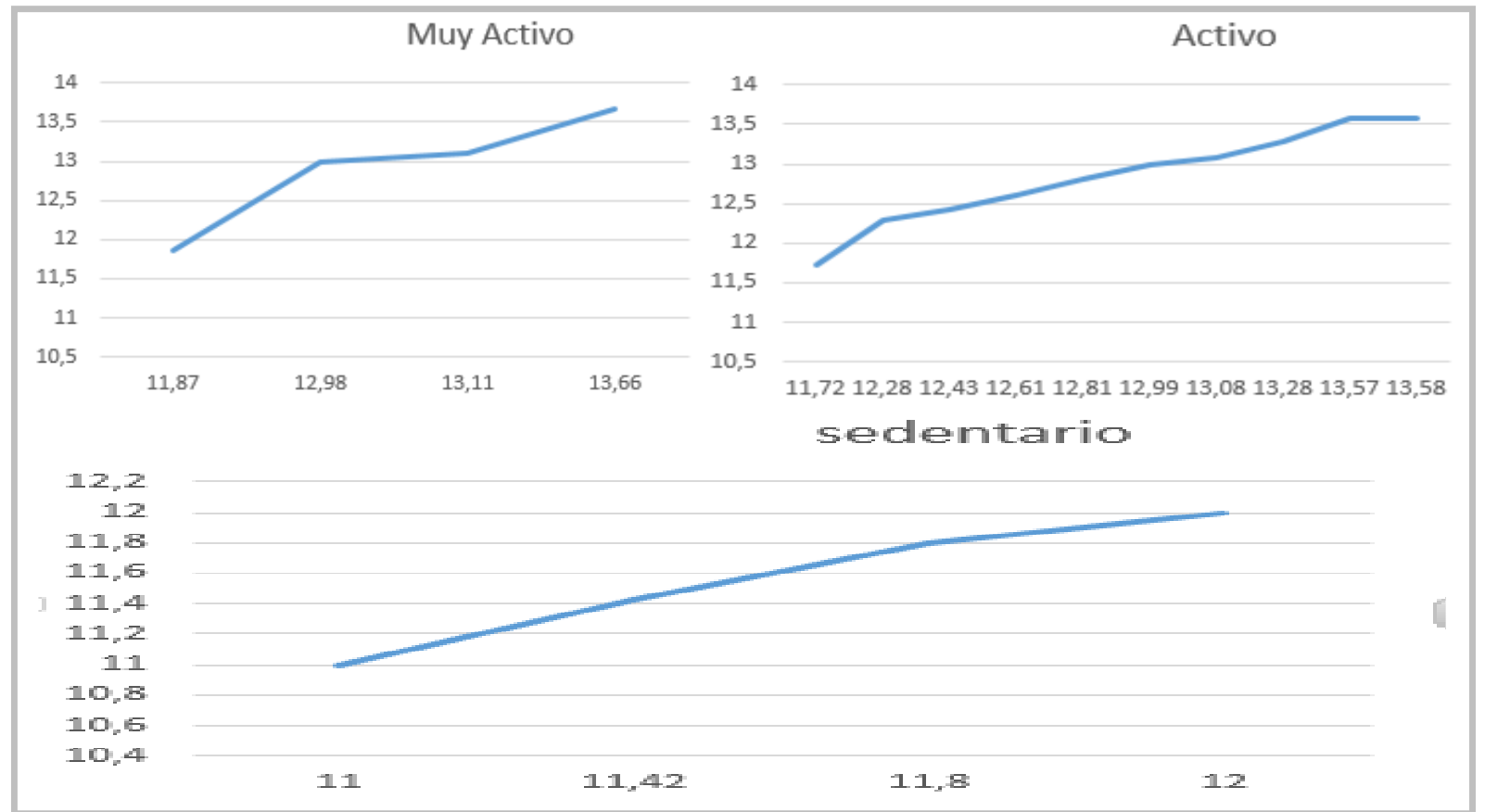

Grafica: "comportamiento general del pedaleo en carga efectiva, según la actividad fisica del individuo" 


\section{Carga efectiva.}

La carga efectiva depende de la capacidad de almacenamiento de la batería, este prototipo se implementó con una de $12 \mathrm{~V}$ a $18 \mathrm{Ah}$. De igual forma, depende de las RMP con la que se está generando la carga, ya que al generar las pruebas no todos los individuos tenían un pedaleo constante, lo cual puede variar dependiendo del tiempo de pedaleo y las RPM. Como lo vemos en la tabla siguiente.

\begin{tabular}{|c|c|c|c|}
\hline Genero & Promedio RPM & Voltaje de Carga & Voltaje efectivo \\
\hline Hombre & 107,67 & 13,30 & 12,73 \\
\hline Hombre & 109,75 & 12,90 & 12,32 \\
\hline Mujer & 102,75 & 12,50 & 12,00 \\
\hline Hombre & 126,88 & 14,50 & 13,66 \\
\hline Mujer & 102,20 & 11,80 & 11,42 \\
\hline Hombre & 114,29 & 12,80 & 12,00 \\
\hline Hombre & 121,75 & 13,80 & 13,11 \\
\hline Hombre & 120,71 & 13,50 & 12,99 \\
\hline Hombre & 120,44 & 13,70 & 12,98 \\
\hline Mujer & 104,60 & 13,00 & 12,28 \\
\hline Hombre & 118,67 & 14,20 & 13,57 \\
\hline Mujer & 96,20 & 13,80 & 13,08 \\
\hline Hombre & 104,67 & 13,30 & 12,61 \\
\hline Hombre & 104,00 & 14,05 & 13,28 \\
\hline Mujer & 109,20 & 13,60 & 12,81 \\
\hline
\end{tabular}




\begin{tabular}{|c|c|c|c|} 
Hombre & 105,30 & 13,10 & 11,87 \\
\hline Mujer & 93,75 & 11,70 & 11,00 \\
\hline Hombre & 109,38 & 13,80 & 13,28 \\
\hline
\end{tabular}

La carga generada, es la carga tomada desde el multímetro, cuando el individuo se detuvo al pedalear. La carga efectiva, es la carga observada después de un tiempo mayor a 15 minutos, al dejar que la batería en reposo.

De esta manera podemos determinar qué porcentaje de la carga generada, la batería está reteniendo para ser almacenada, y cual porcentaje se está perdiendo.

$$
\begin{aligned}
& \text { Voltaje Generad } a_{\text {Prom }}=3.40 \mathrm{v} \\
& \text { Voltaje Efectiva }_{\text {Prom }}=2.71 \mathrm{v}
\end{aligned}
$$

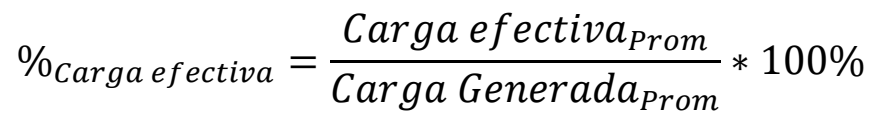

$$
\begin{aligned}
& \%_{\text {carga efectiva }}=\frac{2.71 v}{3.4 v} * 100 \% \\
& \%_{\text {carga efectiva }}=0.7970 * 100 \% \\
& \%_{\text {carga efectiva }}=79.70 \% \approx 80 \%
\end{aligned}
$$

Podemos caracterizar que para esta batería, la carga efectiva sobre la carga total generada, es aproximadamente del $80 \%$, por lo cual el $20 \%$ faltante son perdidas.

\begin{tabular}{|c|c|c|c|c|c|c|c|}
\hline Dispositivo & $\begin{array}{c}\text { Tiempo } \\
\text { de } \\
\text { Inicio }\end{array}$ & $\begin{array}{c}\text { Voltaje } \\
\text { de } \\
\text { Inicio }\end{array}$ & $\begin{array}{c}\text { Tiempo } \\
\text { final }\end{array}$ & $\begin{array}{c}\text { Voltaje } \\
\text { final }\end{array}$ & $\begin{array}{l}\text { Diferencial } \\
\text { de tiempo }\end{array}$ & $\begin{array}{l}\text { Diferencial } \\
\text { de Voltaje }\end{array}$ & Novedades \\
\hline $\begin{array}{c}\text { Bombillo } \\
15 W\end{array}$ & $\begin{array}{c}03: 32 p . \\
m .\end{array}$ & 12,33 & $\begin{array}{l}09: 30 \\
\text { p. m. }\end{array}$ & 10,2 & $05: 58$ & 2,13 & $\begin{array}{c}\text { Descarga } \\
\text { completa de } \\
\text { batería }\end{array}$ \\
\hline $\begin{array}{c}\text { Bombillo } \\
110 \mathrm{~W}\end{array}$ & $\begin{array}{c}\text { 03:00 p. } \\
\text { m. }\end{array}$ & 12,28 & $\begin{array}{l}\text { 05:00 } \\
\text { p. m. }\end{array}$ & 10,1 & 02:00 & 2,18 & $\begin{array}{c}\text { Descarga } \\
\text { completa de } \\
\text { batería }\end{array}$ \\
\hline
\end{tabular}

\section{$>$ Descarga batería de almacenamiento.}

Para determinar la durabilidad de la batería, se realizó pruebas con diferentes dispositivos de uso diario por cualquier persona. 


\begin{tabular}{|c|c|c|c|c|c|c|c|}
\hline $\begin{array}{c}\text { Celular } \\
\text { (Batería } \\
1,85 W h)\end{array}$ & $\begin{array}{c}03: 40 \text { p. } \\
\text { m. }\end{array}$ & 12,53 & $\begin{array}{c}05: 42 \\
\text { p. m. }\end{array}$ & 12,49 & $02: 02$ & 0,04 & $\begin{array}{c}\text { Descarga } \\
\text { parcial de la } \\
\text { batería }\end{array}$ \\
\hline MP3 & $\begin{array}{c}05: 30 \text { p. } \\
\text { m. }\end{array}$ & 11,7 & $22: 00$ & 11,1 & $04: 30$ & 0,6 & $\begin{array}{c}\text { Descarga } \\
\text { parcial de la } \\
\text { batería }\end{array}$ \\
\hline
\end{tabular}

Tabla: "Tiempo funcionamiento con dispositivos"

Para este análisis, solamente tomaremos los dos dispositivos que descargaron por completo la batería.

\begin{tabular}{|c|c|c|}
\hline Dispositivo & $\begin{array}{c}\text { Tiempo de } \\
\text { funcionamiento }\end{array}$ & $\begin{array}{c}\text { Voltaje } \\
\text { consumido }\end{array}$ \\
\hline $\begin{array}{c}\text { Bombillo } \\
15 W\end{array}$ & 6 horas aprox. & 2.13 \\
\hline $\begin{array}{c}\text { Bombillo } \\
110 \text { W }\end{array}$ & 2 horas aprox. & 2.18 \\
\hline
\end{tabular}

Tabla: "Descarga completa de la bateria"

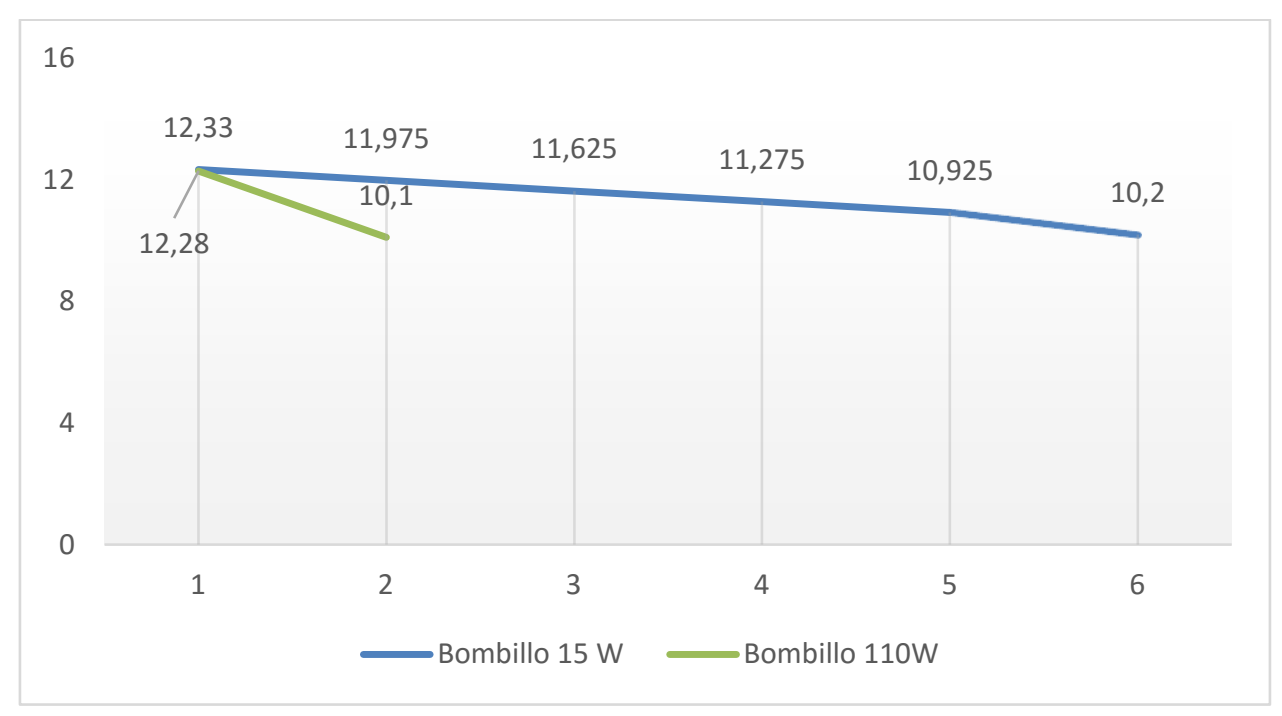

Grafica: "Descarga de la bateria en funcion del tiempo"

Considerando que el mayor rendimiento de tiempo es el bombillo ahorrador de 15 watts, tenemos en cuenta que:

Consumo bombillo: 15 Watt

Consumo corriente bombillo: $0,125 \mathrm{~A}$ 
Voltaje: 120 VAC

Promedio rendimiento del alternador: 45 Watt

Capacidad batería: 216 Watt

Tiempo que dura cargar la batería por hora de funcionamiento:

$$
\frac{15 W}{45 W}=0,33 \text { horas }=20 \text { minutos }
$$

Tiempo de descarga la batería:

$$
\frac{\text { Carga de la Bateria }}{\text { Consumo electrico dispositivo }}=\frac{216 \mathrm{w}}{15 \mathrm{w}}=14,4 \text { horas }=14 \text { horas } 24 \text { minutos }
$$

Considerando que la energía para su funcionamiento se toma de un inversor de corriente de $12 \mathrm{v}$ a $120 \mathrm{v}$, hay que tener en cuenta el consumo del inversor que es proporcional $50 \%$ de la carga.

Consumo bombilla: $15 w * 1.5=22,5 w$

En conclusión, el funcionamiento de la bombilla con la batería full carga debería ser de $9,6 \mathrm{~h}=9$ horas y 36 minutos.

Sin embargo al realizar la prueba con este prototipo, con un bombillo de $15 \mathrm{~W}$, se observa que nos permite una durabilidad de 6 Horas ininterrumpidas de total funcionamiento.

Se determinó que existe un factor dado por el fabricante de la batería donde muestra el funcionamiento con el pasar del tiempo.

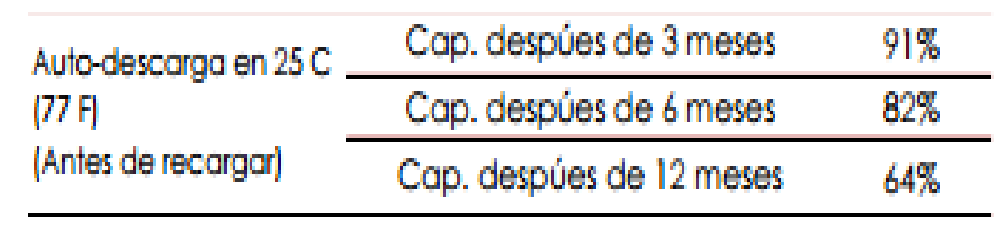

Imagen: "capacidad de la bateria despues de un tiempo de uso"

Para usar la bombilla ahorradora durante 1 hora se debe pedalear 20 minutos aproximadamente. 


\section{$>$ Costos y ahorro de energía.}

Este prototipo se diseñó en una etapa inicial para que se ubicara en la iluminación de un polideportivo, ubicado en la escuela de Cazucá, se nos indica que este polideportivo deja encendida la luz toda la noche. Podemos suponer que a partir de las 6 de la tarde hasta las 6 am que empieza a amanecer. Esto da un tiempo de 12 horas en el que el bombillo funciona encendido.

Se detalló que el bombillo usado es uno de luz cálida a 100 Watts.

\section{Cuadro comparativo:}

\begin{tabular}{|c|c|c|}
\cline { 2 - 3 } \multicolumn{1}{c|}{} & $\begin{array}{c}\text { Bombillo } \\
\text { 100W }\end{array}$ & $\begin{array}{c}\text { Bombillo } \\
\mathbf{1 5 W}\end{array}$ \\
\hline $\begin{array}{c}\text { Consumo en 12 } \\
\text { Horas }\end{array}$ & $1.2 \mathrm{KWh}$ & $0.18 \mathrm{KWh}$ \\
\hline Costo KWh & 437 pesos & 437 pesos \\
\hline $\begin{array}{c}\text { Valor consumo por } \\
\mathbf{1 2} \text { Horas }\end{array}$ & 524,4 pesos & 78.66 pesos \\
\hline $\begin{array}{c}\text { Consumo durante 30 } \\
\text { días x 12 horas }\end{array}$ & $36 \mathrm{KWh}$ & $5.4 \mathrm{KWh}$ \\
\hline $\begin{array}{c}\text { Valor consumo } \\
\text { durante 30 días por } \\
\mathbf{1 2} \text { Horas }\end{array}$ & 15732 pesos & 2360 pesos \\
\hline \multicolumn{2}{|c|}{ Tabla: "Cuadro comparativo valor de consumo" } \\
\hline
\end{tabular}

Tabla: "Cuadro comparativo valor de consumo"

Con la tabla observamos que tener un bombillo de $100 \mathrm{~W}$ durante 12 horas genera un consumo 6 veces mayor al que me genera un bombillo de $15 \mathrm{~W}$, durante el mismo intervalo de tiempo.

\section{Ahorro estimado con el prototipo implementado:}

Ya se observó que con una batería de $12 \mathrm{~V}$ a $18 \mathrm{Ah}$ y un bombillo de $15 \mathrm{~W}$, obtenemos una duración de 6 horas. Durante este tiempo de uso se puede estimar un ahorro de:

\begin{tabular}{|c|c|}
\cline { 2 - 2 } \multicolumn{1}{c|}{} & Bombillo 15W \\
\hline $\begin{array}{c}\text { Consumo en } 6 \\
\text { Horas }\end{array}$ & $0.09 \mathrm{KWh}$ \\
\hline Costo KWh & 437 pesos \\
\hline $\begin{array}{c}\text { Valor consumo } \\
\text { por } 6 \text { Horas }\end{array}$ & 39.33 pesos \\
\hline
\end{tabular}




\begin{tabular}{|c|c|}
$\begin{array}{c}\text { Consumo } \\
\text { durante } 30 \text { días } \\
\text { x } 6 \text { horas }\end{array}$ & $2.7 \mathrm{KWh}$ \\
\hline $\begin{array}{c}\text { Valor consumo } \\
\text { durante } 30 \text { días } \\
\text { por } 6 \text { Horas }\end{array}$ & 1180 pesos \\
\hline
\end{tabular}

Tabla: "Cuadro estimacion de ahorro durante 30 dias con bombillo de 15W"

Es decir, que si usamos el prototipo estamos estimando un ahorro de 1180 pesos por el uso de un bombillo de $15 \mathrm{~W}$ durante 12 horas por 30 días, aproximadamente el $50 \%$ del valor del consumo total. $Y$ un ahorro de aproximadamente 14 mil pesos con respecto al uso del bombillo de $110 \mathrm{~W}$.

\section{Métricas características del prototipo.}

\section{CARACTERISTICAS PRINCIPALES}

\begin{tabular}{|c|c|c|c|c|c|c|}
\hline \multicolumn{5}{|c|}{ Elementos fundamentales } & \multirow{2}{*}{\multicolumn{2}{|c|}{ Tiempo Cargue de batería }} \\
\hline \multirow{2}{*}{$\begin{array}{l}\text { Dispositivos } \\
\text { Alternador }\end{array}$} & \multirow{2}{*}{$\begin{array}{c}\text { Voltaje } \\
12 \mathrm{~V}\end{array}$} & \multirow{2}{*}{$\begin{array}{c}\text { corriente } \\
65 \mathrm{~A}\end{array}$} & \multirow{2}{*}{\begin{tabular}{|c|}
$\begin{array}{c}\text { Rango de } \\
\text { carga }\end{array}$ \\
-
\end{tabular}} & \multirow{2}{*}{$\begin{array}{c}\text { Potencia } \\
780 \\
\text { W(generada) }\end{array}$} & & \\
\hline & & & & & Mínimo & Máximo \\
\hline Batería & $12 \mathrm{~V}$ & 18Ah & $12.5 \mathrm{~V}-13.5 \mathrm{~V}$ & $\begin{array}{c}216 \\
\text { W(almacenada) }\end{array}$ & 17 minutos & 1 hora \\
\hline \multicolumn{5}{|c|}{ Bicicleta } & & \\
\hline $\begin{array}{c}\text { RPM } \\
\text { Generadas }\end{array}$ & \multicolumn{4}{|c|}{ Potencia promedio generada pedaleo } & & \\
\hline 2450 & \multicolumn{4}{|c|}{296 watts } & & \\
\hline \multicolumn{7}{|c|}{ METRICAS } \\
\hline \multicolumn{2}{|c|}{$\begin{array}{l}\text { RPM Generadas por } \\
\text { genero }\end{array}$} & \multicolumn{3}{|c|}{$\begin{array}{l}\text { Voltaje Generado según actividad física del } \\
\text { individuo sin distinción de sexo }\end{array}$} & \multicolumn{2}{|c|}{ Carga Efectiva } \\
\hline Hombre & 123.4 & Actividad & Mínimo & Máximo & \multicolumn{2}{|c|}{$\begin{array}{l}80 \% \text { (sobre la carga } \\
\text { generada) }\end{array}$} \\
\hline Mujer & 108 & $\begin{array}{l}\text { Sedentar } \\
\text { io }\end{array}$ & $1.5 \mathrm{~V}$ & $2.7 \mathrm{~V}$ & \multicolumn{2}{|c|}{$\begin{array}{c}\text { Tiempo descarga de la } \\
\text { Batería }\end{array}$} \\
\hline \multicolumn{2}{|c|}{$\begin{array}{l}\text { RPM necesarias para } \\
\text { generar } 1 \text { Voltio }\end{array}$} & Activo & $1.98 \mathrm{~V}$ & $3.61 \mathrm{~V}$ & Bombillo $100 \mathrm{~W}$ & 2 Horas \\
\hline \multicolumn{2}{|c|}{120 RPM } & $\begin{array}{c}\text { Muy } \\
\text { activo }\end{array}$ & $2.67 \mathrm{~V}$ & $2.84 \mathrm{~V}$ & Bombillo 15W & 6 Horas \\
\hline \multicolumn{3}{|c|}{ Costos y ahorro con bombillo $15 \mathrm{~W}$} & & & & \\
\hline Costos & $\begin{array}{l}2360 \\
\text { pesos }\end{array}$ & \multirow{2}{*}{$\begin{array}{l}50 \% \text { de } \\
\text { ahorro }\end{array}$} & & & & \\
\hline Ahorro & $\begin{array}{l}1180 \\
\text { pesos }\end{array}$ & & & & & \\
\hline
\end{tabular}


Tabla comparativa con otras fuentes de energía.

\begin{tabular}{|c|c|c|c|}
\hline Tipo de Energía & Origen & Potencial & Clasificación \\
\hline Energía del Carbón & $\begin{array}{c}\text { Se encuentra en la transformación } \\
\text { de masas vegetales enterradas bajo } \\
\text { el subsuelo y sometidas a métodos } \\
\text { de descomposición }\end{array}$ & Madera: $5491 \mathrm{KWh} / \mathrm{Kg}$ & No renovable \\
\hline $\begin{array}{l}\text { Energía del } \\
\text { petróleo y gas } \\
\text { natural }\end{array}$ & $\begin{array}{l}\text { Se deriva de organismos } \\
\text { microscópicos que se crían en las } \\
\text { aguas superficiales de los océanos. }\end{array}$ & $\begin{array}{l}1 \mathrm{~kg} \text { de petróleo } \\
\text { equivale a } 11 \mathrm{kWh}\end{array}$ & No renovable \\
\hline Energía solar & Energía radiante procedente del Sol & $\begin{array}{l}\text { Es variable, en función } \\
\text { de la hora del día, } \\
\text { época del año y } \\
\text { situación atmosférica. } \\
\text { La radiación media } \\
\text { incidente por m2 fuera } \\
\text { de la atmosfera es de } \\
1,4 \mathrm{~kW} / \mathrm{m} 2\end{array}$ & Renovable \\
\hline Energía Eólica & $\begin{array}{c}\text { Se encuentra en la existencia sobre } \\
\text { la tierra de masas de aire a } \\
\text { diferentes temperaturas }\end{array}$ & $\begin{array}{l}\text { Es variable, en función } \\
\text { de la hora del día, } \\
\text { época del año y } \\
\text { topografía local. Un } \\
\text { viento de } 13 \mathrm{~m} / \mathrm{s} \text {, a } \\
\text { través de una superficie } \\
\text { de } 150 \mathrm{~m} 2 \text { tiene una } \\
\text { potencia de } 198 \mathrm{~kW}\end{array}$ & Renovable \\
\hline Energía del Oleaje & $\begin{array}{c}\text { Es la acción del viento sobre la } \\
\text { superficie del agua }\end{array}$ & $\begin{array}{c}\text { El potencial energético } \\
\text { de las olas se estima en } \\
0,5 \mathrm{TW}\end{array}$ & Renovable \\
\hline Energía Hidráulica & $\begin{array}{l}\text { Se obtiene de cualquier masa de } \\
\text { agua en movimiento. }\end{array}$ & $\begin{array}{l}\text { 1Tn de agua a } 10 \mathrm{~m} \text { de } \\
\text { altura, tiene una } \\
\text { energía de } 278 \mathrm{KWh}\end{array}$ & Renovable \\
\hline $\begin{array}{c}\text { Energía Mecánica } \\
\text { (bicigenerador) }\end{array}$ & $\begin{array}{l}\text { Se deriva del pedaleo de una } \\
\text { bicicleta, dependiendo de sus } \\
\text { características de diseño }\end{array}$ & $\begin{array}{c}1 \text { hora de pedaleo, con } \\
\text { una batería de } 12 \mathrm{~V} \text { - } \\
\text { 18Ah, se puede generar } \\
216 \mathrm{~W}\end{array}$ & Renovable \\
\hline
\end{tabular}

Tabla: "Cuadro comparativo con otro tipo de energias renovables"[14] 


\section{ADMINISTRACIÓN DEL PROYECTO}

En la siguiente tabla se relaciona el costo aproximado para la creación de este proyecto.

\begin{tabular}{c|c|c} 
Ítem & Cantidad & Valor \\
\hline Bicicleta estática de segunda mano & 1 & $\$ 200.000$ \\
\hline Batería & 1 & $\$ 72.000$ \\
\hline Alternador & 1 & $\$ 100.000$ \\
\hline Controlador de energía & 1 & $\$ 90.000$ \\
\hline Interruptor & 1 & $\$ 2.000$ \\
\hline Multímetro & 1 & $\$ 15.000$ \\
\hline Correa de transmisión & 1 & $\$ 10.000$ \\
\hline Cables de corriente & $10 \mathrm{mts}$ & $\$ 16.000$ \\
\hline Adecuación para bicicleta & & $\$ 80.000$ \\
\hline Cajilla de protección & & $\$ 90.000$ \\
\hline Tornillos, entre otros & & $\$ 3.500$ \\
\hline Inversor & 1 & $\$ 60.000$ \\
\hline & Total & $\$ 738.500$
\end{tabular}




\section{CONCLUSIONES}

1. A medida que el tiempo pasa las energías no renovables se van consumiendo y agotando, cada día somos más personas que habitamos este planeta, y por tal motivo es indispensable buscar alternativas que nos permita suplir todo el consumo energético del mundo. Actualmente han surgido varias alternativas, un ejemplo de estos, es el Bicigenerador, como lo he llamado, el cual nos permite generar energía con el pedaleo de una bicicleta. Con la implementación de este prototipo, se validó que es una de las alternativas más económicas que se pueden encontrar, debido que para su implementación contamos con elementos no tan costosos, que se pueden conseguir de segunda mano, lo cual nos ayuda a reducir costos.

2. Este prototipo fue diseñado hasta la fase de almacenamiento, se usaron baterías de plomo ácido, las cuales están diseñadas para soportar descargas muy bajas, sin embargo, es recomendable no dejar estas baterías conectadas al prototipo si su uso no es constante, esto puede generar una descarga muy alta y al generar una carga esta no se mantiene. Para este prototipo se generó una parametrización de carga, donde del $100 \%$ de la carga generada por el alternador y recibida por la batería, el $80 \%$ es efectiva y el $20 \%$ restante, perdidas. Esta perdida de almacenamiento, se presenta debido a una disipación de calor en la estructura del bicigenerador, es decir, el alternador se encuentra haciendo masa con alguna parte metálica. Sin embargo, para solucionar este inconveniente se debe de aislar el alternador de la estructura, pero en este prototipo no se realizo esta medida, debido a que se debía desajustar totalmente y esto implicaba un cambio en los parámetros ya establecidos. 
3. Inicialmente se propuso que las pruebas se realizarían en una población de niños de la comunidad de Cazucá, sin embargo, esto no puedo ser posible porque en primera instancia el prototipo de prueba se situó en mi lugar de residencia, optando por realizar las pruebas con los niños cerca a mi residencia, sin embargo solo obtuve resultados con dos niños, ya que no fue posible ubicar niños donde sus padres permitieran realizar estas pruebas. Esto mismo sucedía con los niños de Cazucá, no era posible que ellos se desplazara hasta mi lugar de residencia, y tampoco era viable que llevara el prototipo hasta El Arroyo, inicialmente por costos de movilidad y que el prototipo quedaría sin custodia de alguna persona. Para dar continuidad a la etapa de pruebas, se decidió ubicar el prototipo en la universidad Santo Tomas, en el área de laboratorios, y solicitar a personas que asistían al gimnasio de su colaboración para culminar las pruebas.

4. Las pruebas realizadas permitieron determinar el desempeño que puede tener este tipo de prototipo en un hogar, donde permite, generar un ahorro mínimo, que con el tiempo puede llegar a ser un valor representativo en las cuentas de un hogar. Cabe resaltar que si la capacidad de la batería es mucho mayor que con la que se realizaron las pruebas, o se implementa un banco de baterías lo suficiente grande, este puede llegar a suplir la energía diaria de un hogar.

5. La fase inicial de pruebas del dispositivo, permitió identificar una métrica comparativa, donde se concluye que para su uso óptimo en términos de durabilidad y rendimiento de la batería, un bombillo ahorrador de $15 \mathrm{~W}$, permite un consumo constante durante 6 horas. Sin embargo, en el mercado se encuentra bombillos Led con consumo de hasta $6 \mathrm{~W}$, esto permitiría que el uso del prototipo sea por mucho más tiempo del resultado obtenido en las pruebas. 
6. Es de nuestro conocimiento que existen en el mercado diferentes tipos de energías ya sean renovables o no renovables, y aunque son mucho más eficientes, ya que no dependen del ser humano para ser generadas, considero que este tipo de implementación como lo es el bicigenerador, está más al alcance de cualquier persona para ser construido, donde se puede acceder a los elementos necesarios de segunda mano a un costo favorable. Para este caso en particular, se pueden generar hasta $216 \mathrm{~W}$, en un pedalero de aproximadamente 1 hora. Sin embargo esto puede variar dependiendo de las características físicas del individuo que esté generando el pedaleo.

7. El impacto que puede generar en una comunidad, es bastante alto, donde se puede atacar factores como la economía, la salud e inclusive el empleo. Cuando el individuo pedalea está ejercitando su cuerpo, si esto se vuelve algo constante y diario, su condición física llega a mejorar, mientras va generando energía eléctrica que es almacenada y posteriormente utilizada. Esto podría conllevar a tener una energía sustentable, amigable con el ambiente y con nuestro bolsillo, ya que si llegamos a generar más energía en KWh de la que nos proporciona la empresa prestadora del servicio eléctrico, puede haber una remuneración por parte de la empresa, ya que ellos estarían haciendo uso de esta energía, que estamos generando.

8. Uno de los factores que afectan a estas comunidades, es el desempleo. Un sistema sin grandes complejidades, como este prototipo puede ser implementado por cualquier persona interesada, con la debida capacitación y así llegar a ayudar a que más personas obtengan un beneficio propio a partir del pedaleo de una bicicleta. 


\section{BIBLIOGRAFÍA}

[1] http://www.saliendodelcallejon.pnud.org.co/img upload/1433f8d9ffdce21262b03 4f353875ed6/cron altoscazuca.pdf

[2] http://www.mercadofitness.com/blog/noticias/the-green-microgym-un-gimnasionorteamericano-que-piensa-en-verde/

[3] http://professionalautomotive.wordpress.com/2012/06/30/el-alternador-principiode-funcionamiento/

[4] http://www.aficionadosalamecanica.net/alternador-funcionam.htm

[5] http://www.bateriascarpinelli.com.ar/carpinelli/manual folder/MMBVer50527 AF . .pdf

[6] http://www.olajedatos.com/documentos/baterias plomo.pdf

[7] Proyecto: "Diseño de un sistema de generación de energía eléctrica a partir de bicicletas estática" por Karl Von Drais y Thomas McCal.

[8] http://www.mienergiagratis.com/proyectos/22.pdf

[9] http://www.si3ea.gov.co/EnergiaAlternativa/index.swf

[10] http://evolucionverde.es/bicigeneradores-un-nuevo-horizonte/

[11] http://www.agora.ulpgc.es/ficheros/INTRODUCCION_RENOVABLES.pdf

[12] http://www.amazon.com/Pedal-Power-Bicycle-Generator-

Maximum/dp/B009NWK8EE/ref=pd sim sbs lg 6?ie=UTF8\&refRID $=013 \mathrm{H} 2 \mathrm{NR} 0 \mathrm{Z}$ 978W469MWY0

[13] http://www.regenbat.com/reacciones-quimicas-regenbat-regeneracionbaterias.php

[14] https://es.scribd.com/doc/110921277/Cuadro-Comparativo-sobre-los-Tiposde-Energia-Renovables-y-No-Renovables 


\section{ANEXOS}

Referencia

TB12-18 (12V18AH)

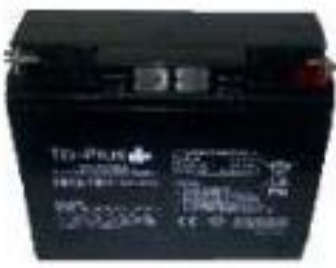

Dimensiones y Caracteristicas
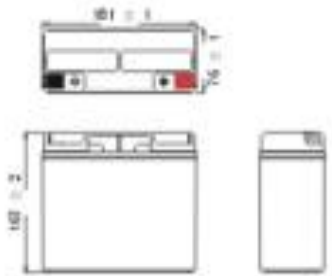

\begin{tabular}{|c|c|c|}
\hline Teralón nomind & & $12 \mathrm{~V}$ \\
\hline $\begin{array}{l}\text { Capacidad nomin } \\
\text { de horas) }\end{array}$ & al (20 tosa & 18АН \\
\hline Peso aprovimado & & $5 \mathrm{~kg}$ \\
\hline \multirow{2}{*}{ Termind } & Estondor & B1 -MS \\
\hline & Opcional & \\
\hline Largo mm & & 181 \\
\hline Ancho $\mathrm{mm}$ & & 76 \\
\hline Alio sin teminal mo & & 167 \\
\hline
\end{tabular}

Temperatura de funcionamiento

\begin{tabular}{ll}
\hline Cargo & $0 \mathrm{C}(32 \mathrm{~F})-40 \mathrm{C}(104 \mathrm{~F})$ \\
\hline Descarga & $.20 \mathrm{C}(-4 \mathrm{~F})-50 \mathrm{C}(122 \mathrm{~F})$ \\
\hline Amacenamiento & $.20 \mathrm{C}(-4 \mathrm{~F})-40 \mathrm{C}(104 \mathrm{~F})$ \\
\hline
\end{tabular}

\section{Tecnobaterías *}

Ispecificación

\begin{tabular}{|c|c|c|c|c|}
\hline \multirow{4}{*}{\multicolumn{2}{|c|}{$\begin{array}{l}\text { Capacidad } \\
25 \mathrm{C}(7) \text { ค }\end{array}$}} & 20 tavo de horas & (D.9A) & IB,OAH \\
\hline & & 10 Tava de haras & $(1.52 \mathrm{~A})$ & I6.2AH \\
\hline & & 5 Tasa de horas & $(2.88 \mathrm{~A}$ & 14.4AH \\
\hline & & 1 Tava de horas & $(10,8 \mathrm{~A})$ & $10.8 \mathrm{AH}$ \\
\hline \multirow{4}{*}{\multicolumn{2}{|c|}{$\begin{array}{l}\text { Caoocidod afectoda } \\
\text { por la semperaturo }\end{array}$}} & \multicolumn{2}{|c|}{$40 \mathrm{C}(104 \mathrm{~F})$} & $103 \pi$ \\
\hline & & \multicolumn{2}{|c|}{$25 \mathrm{C} 7 \mathrm{7}$ 月 } & $100 \pi$ \\
\hline & & \multicolumn{2}{|c|}{$0 \mathrm{C}(32 \mathrm{~F})$} & $86 \pi$ \\
\hline & & \multicolumn{2}{|c|}{$-15 \mathrm{C}(5 \mathrm{~F})$} & $65 \%$ \\
\hline \multirow{3}{*}{\multicolumn{2}{|c|}{$\begin{array}{l}\text { Aulo-delcaga en } 25 \mathrm{C} \\
\text { p7 f) } \\
\text { (Anten de recargor) }\end{array}$}} & \multicolumn{2}{|c|}{ Cop. despúes de 3 meves } & $91 \%$ \\
\hline & & \multicolumn{2}{|c|}{ Cop. despúes de 6 meres } & $82 \%$ \\
\hline & & \multicolumn{2}{|c|}{ Cap. despúes de 12 meses } & $64 \pi$ \\
\hline \multirow{2}{*}{$\begin{array}{l}\text { Carga de } \\
\text { surisn } \\
\text { corstante }\end{array}$} & Cicio & \multicolumn{3}{|c|}{$\begin{array}{c}\text { Corriente de carga hiclal es,4A } 14,4 \mathrm{~V}-15 \mathrm{~V} \\
\text { of } 25 \mathrm{C}[77 \mathrm{~F})\end{array}$} \\
\hline & En elipera & \multicolumn{3}{|c|}{$13.5 \mathrm{~V}-13.8 \mathrm{~V}$ at $2 \mathrm{SC} \mid 77 \mathrm{~F}$} \\
\hline \multicolumn{4}{|c|}{ Capocidad mávima de descarga } & $270 \mathrm{~A}$ \\
\hline
\end{tabular}

Caracteristic as de descarga

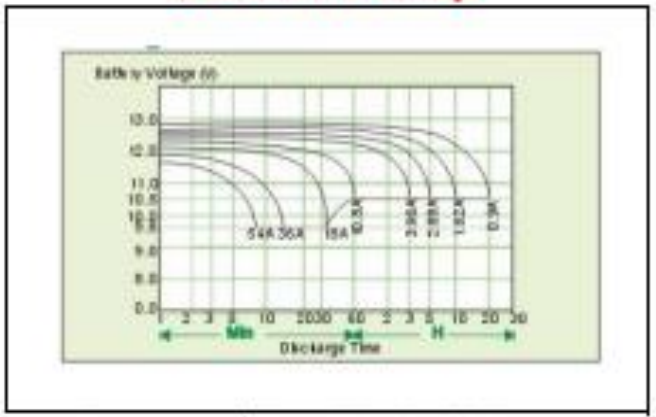

Nola : Descarga sera de corte de 10.5V sil la descarga en $<1 \mathrm{C}$ ren $9 ., \mathrm{V}$ sien $>1 \mathrm{C}$

Se recomienda recaparia baterla a voliqle constonte carga hmediatamente desputs de su uso

Energia de comiente conatante( Amp) y constante (Walt) Tabla de descarga a $25 \mathrm{C}(77$ )

\begin{tabular}{|c|c|c|c|c|c|c|c|c|c|c|c|}
\hline Fral Vollaje & (in i) & 5 & 10 & 15 & 20 & 30 & 60 & 120 & 180 & 300 & 600 \\
\hline \multirow{2}{*}{1,80 VFC } & $\mathrm{A}$ & 73.24 & 4705 & 35.24 & 29.43 & 20.19 & 12.10 & 6.71 & 4.90 & 3.19 & 1.76 \\
\hline & $w$ & 769.00 & 494.00 & 370.00 & 309.00 & 212.00 & 127.00 & 70.50 & 5150 & 33.50 & 18.50 \\
\hline \multirow{2}{*}{1,75 VFC } & $\mathbf{A}$ & 73.52 & 4752 & 35.52 & 29.71 & 20.48 & 12.38 & 7.01 & 5.10 & 3.35 & 1.81 \\
\hline & $w$ & 773.00 & 499.00 & 373.00 & 31200 & 215.00 & 130.00 & 73.66 & 53.57 & 35.21 & 19.00 \\
\hline \multirow{2}{*}{$1,70 \vee P C$} & A & 73.71 & 4731 & 35.71 & 29.90 & 2067 & 12.57 & 7.20 & 5.73 & 3.44 & 1.90 \\
\hline & $w$ & 77400 & 501.00 & 375.00 & 31400 & 217.00 & 132.00 & 75.60 & 55.19 & 36.18 & 20.00 \\
\hline \multirow{2}{*}{1,65 VPC } & A & 73.90 & 47.90 & 35.90 & 30.09 & 2086 & 12.76 & 7.28 & 5.30 & 3.48 & 1.92 \\
\hline & $w$ & 776.00 & 503.00 & 377.00 & 316.00 & 219.00 & 134.00 & 76.46 & 55.62 & 36.60 & 20.20 \\
\hline \multirow{2}{*}{1,60 VPC } & A & 74.10 & 800 & 36.00 & 30.19 & 20.95 & 12.86 & 7.33 & 5.33 & 3.50 & 1.97 \\
\hline & $w$ & 778.00 & 504.00 & 378.00 & 31700 & 2200.00 & 135.00 & 7700 & $56 D 0$ & 36.83 & 20.60 \\
\hline
\end{tabular}

Hoja técnica de la batería de $12 \mathrm{~V}$ - 18Ah 


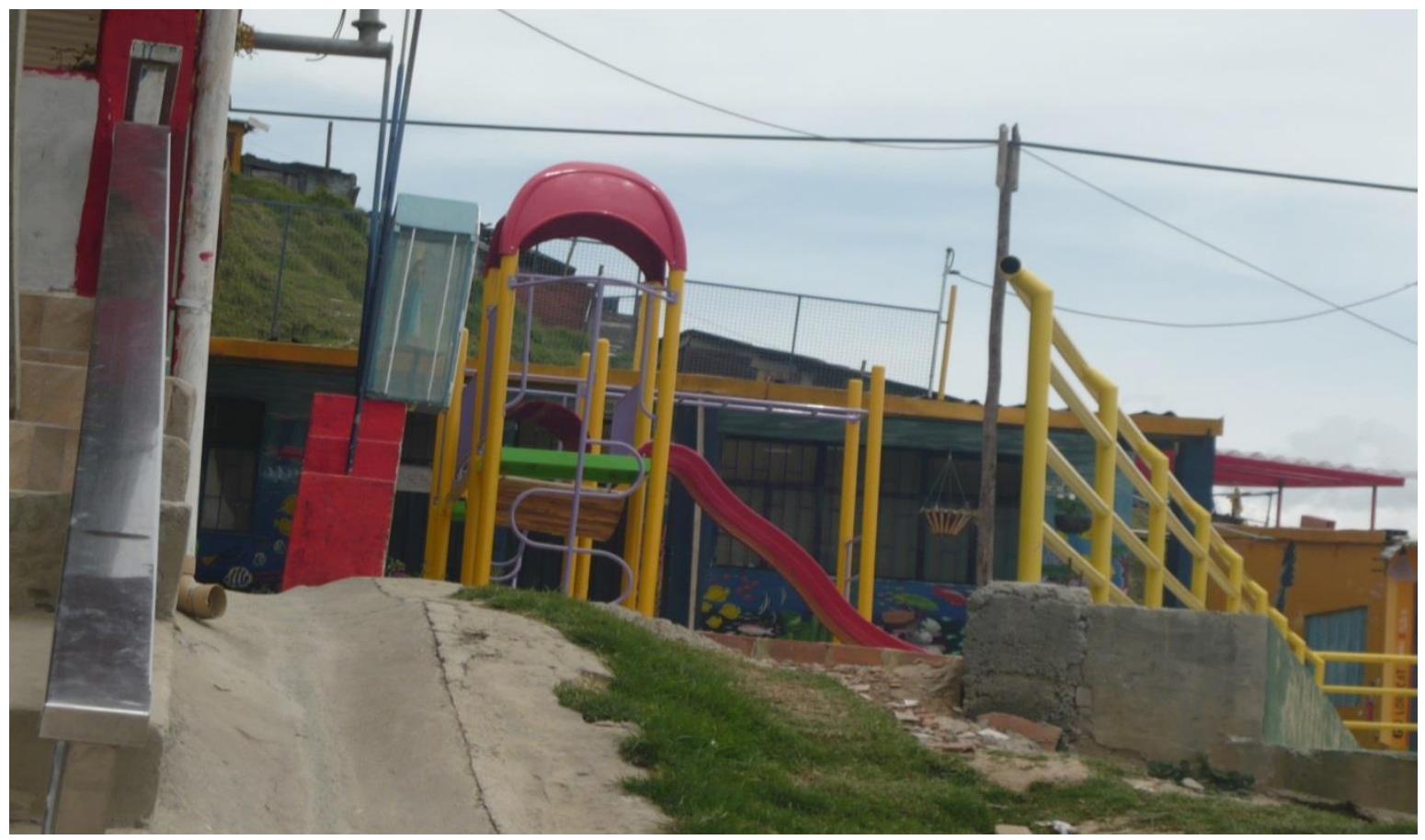

Foto del Parque de juegos de la escuela en El Arroyo por Diana L. Gutiérrez

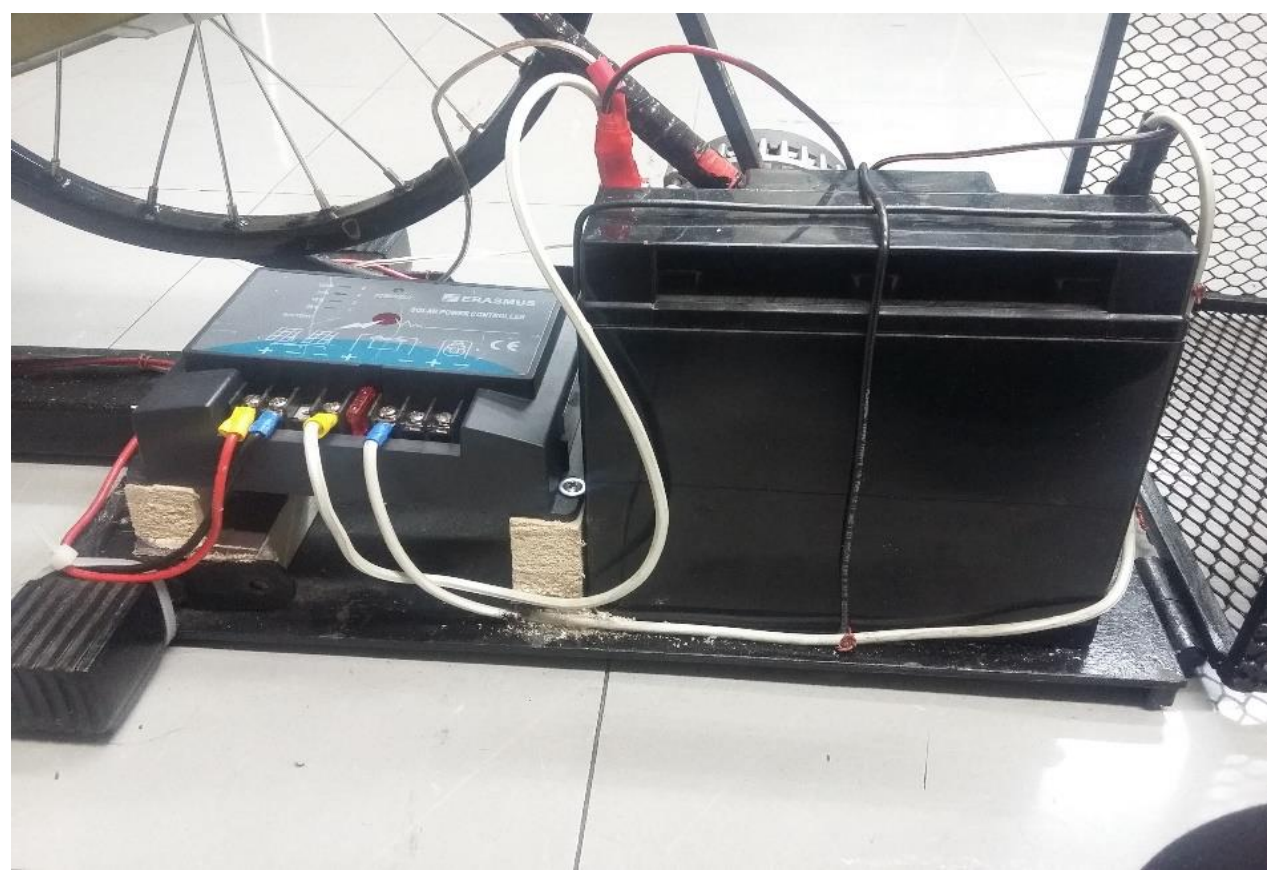

Foto de la batería y controlador de energía por Diana L. Gutiérrez 


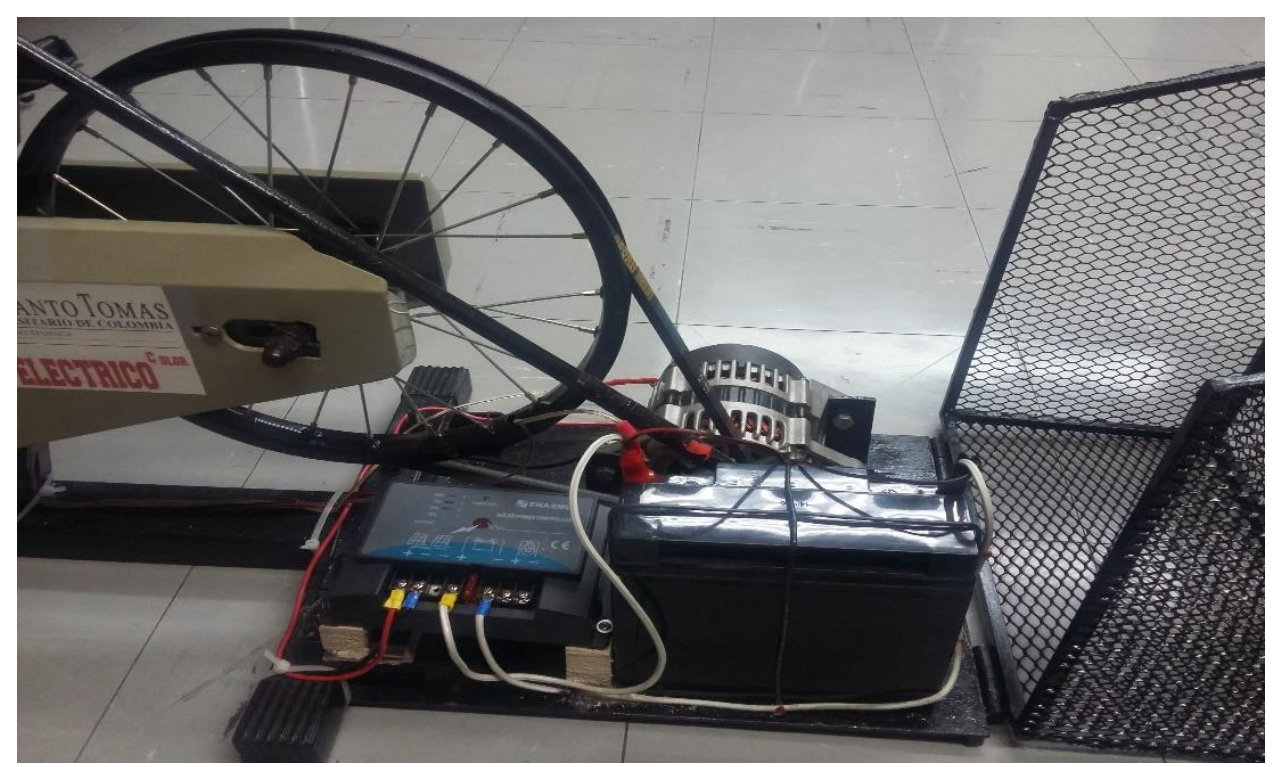

Foto del sistema de almacenamiento de energía por Diana L. Gutiérrez

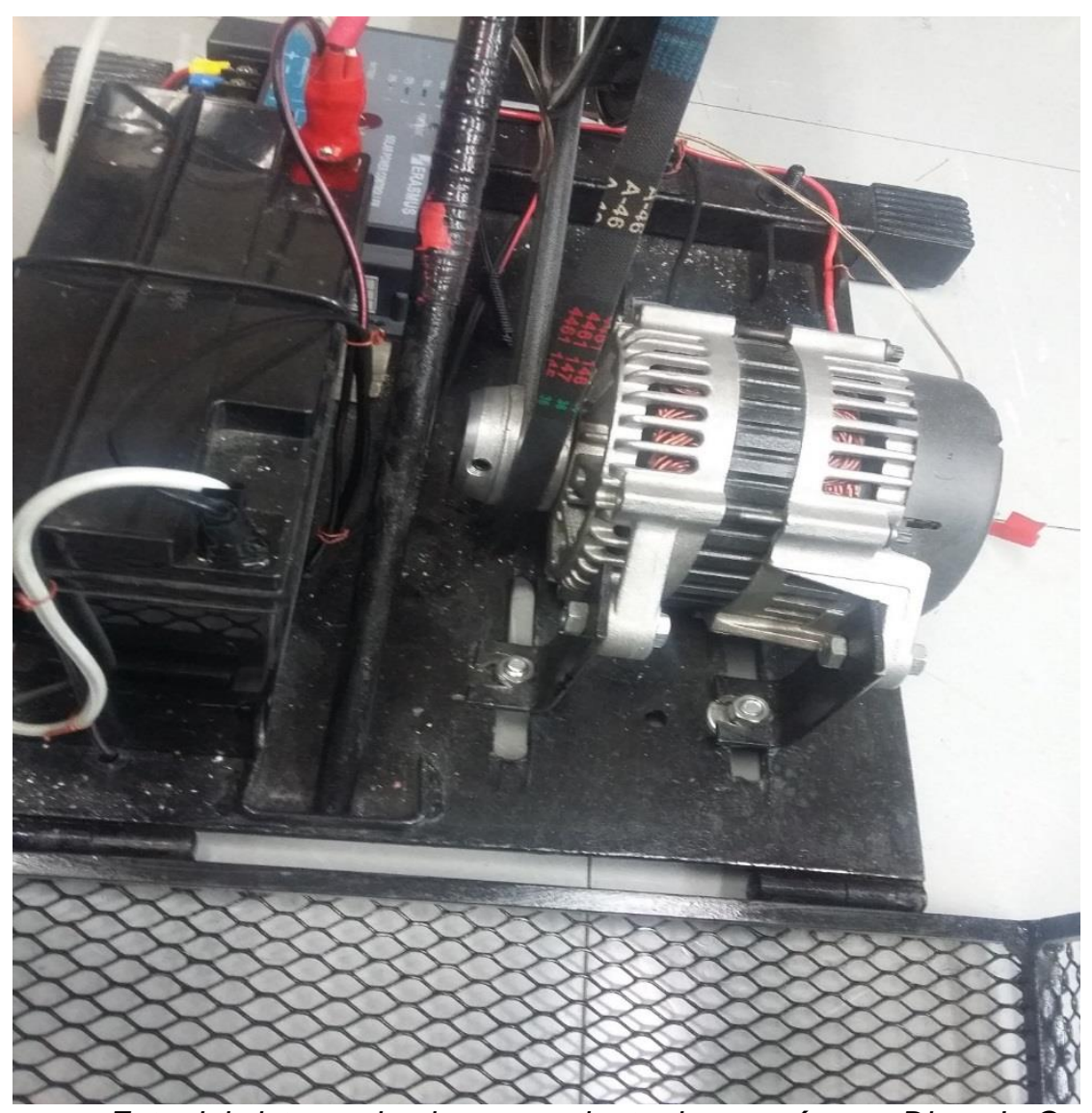

Foto del sistema de almacenamiento de energía por Diana L. Gutiérrez 

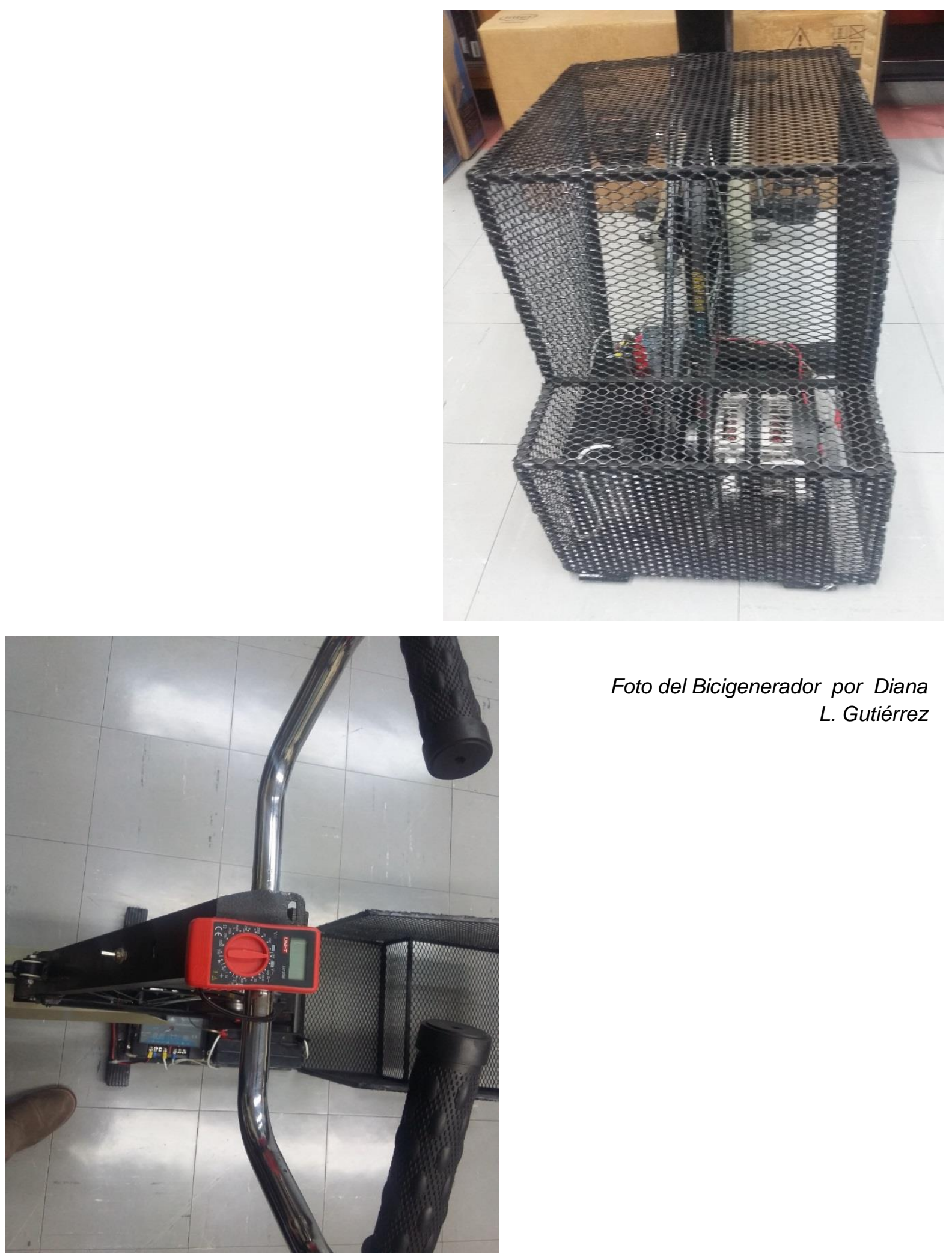

Foto del Bicigenerador por Diana

L. Gutiérrez

Foto perspectiva desde arriba del Bicigenerador

Por Diana L. Gutiérrez 


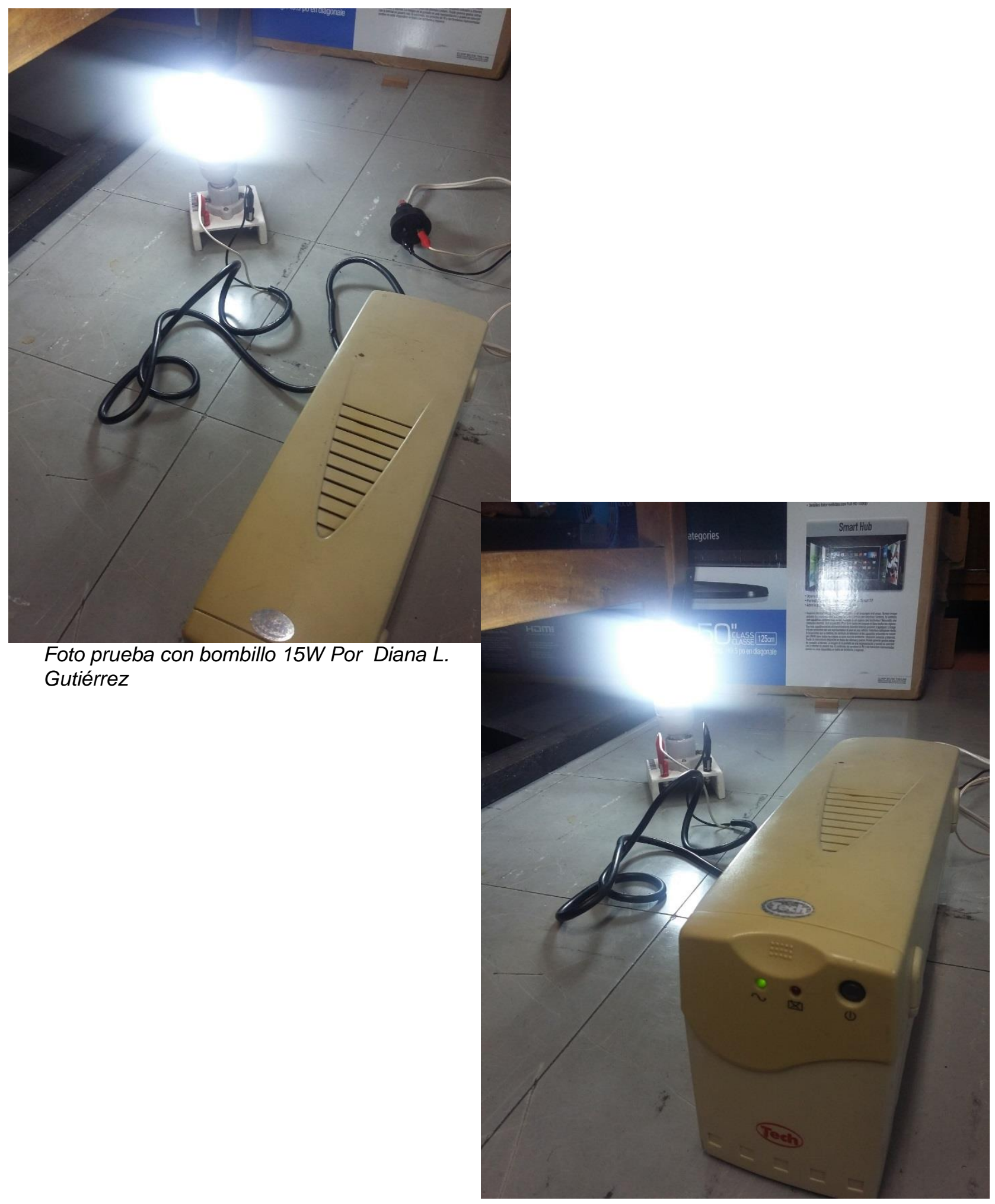

Foto prueba con bombillo 15W Por Diana L. Gutiérrez 

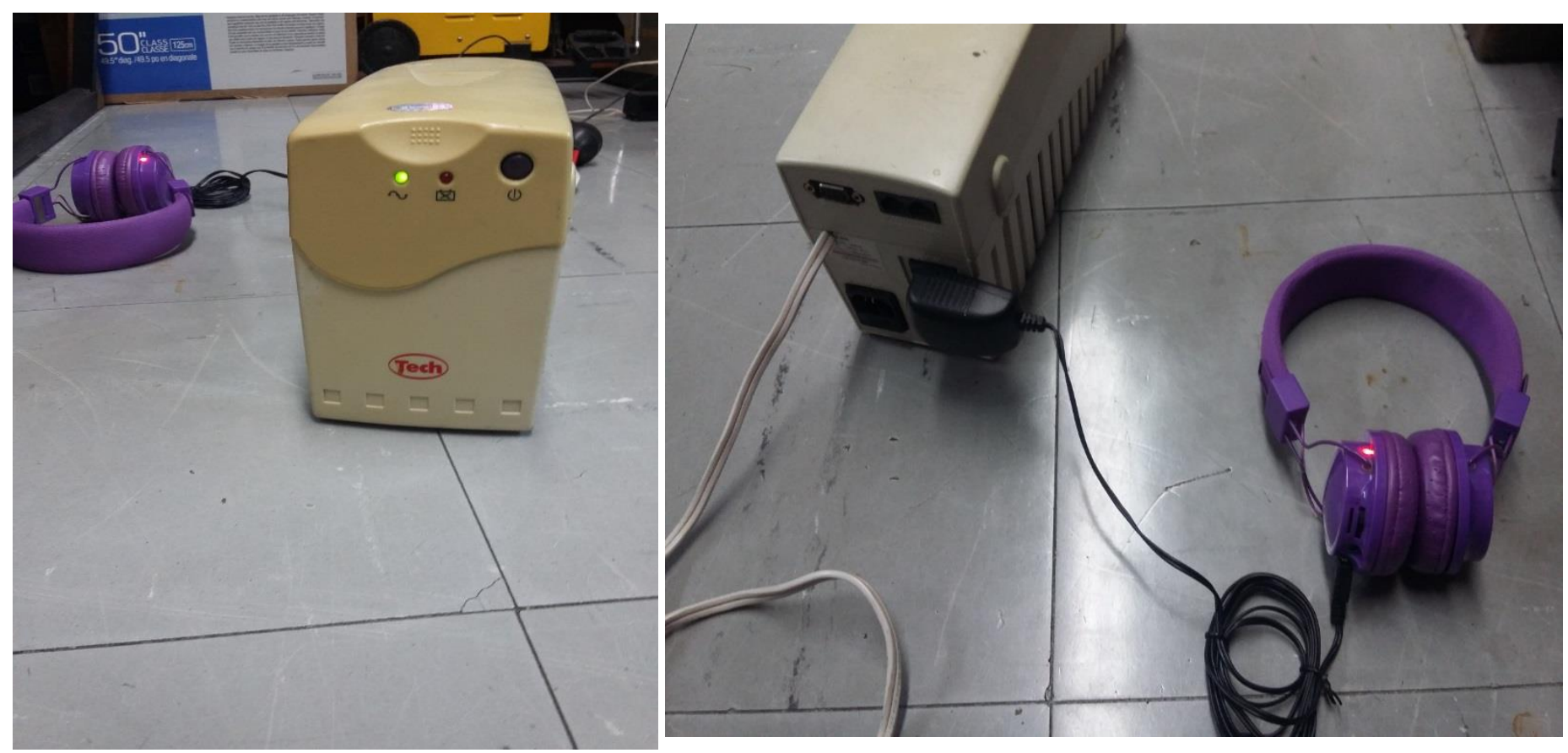

Foto prueba con auriculares mp3 Por Diana L. Gutiérrez

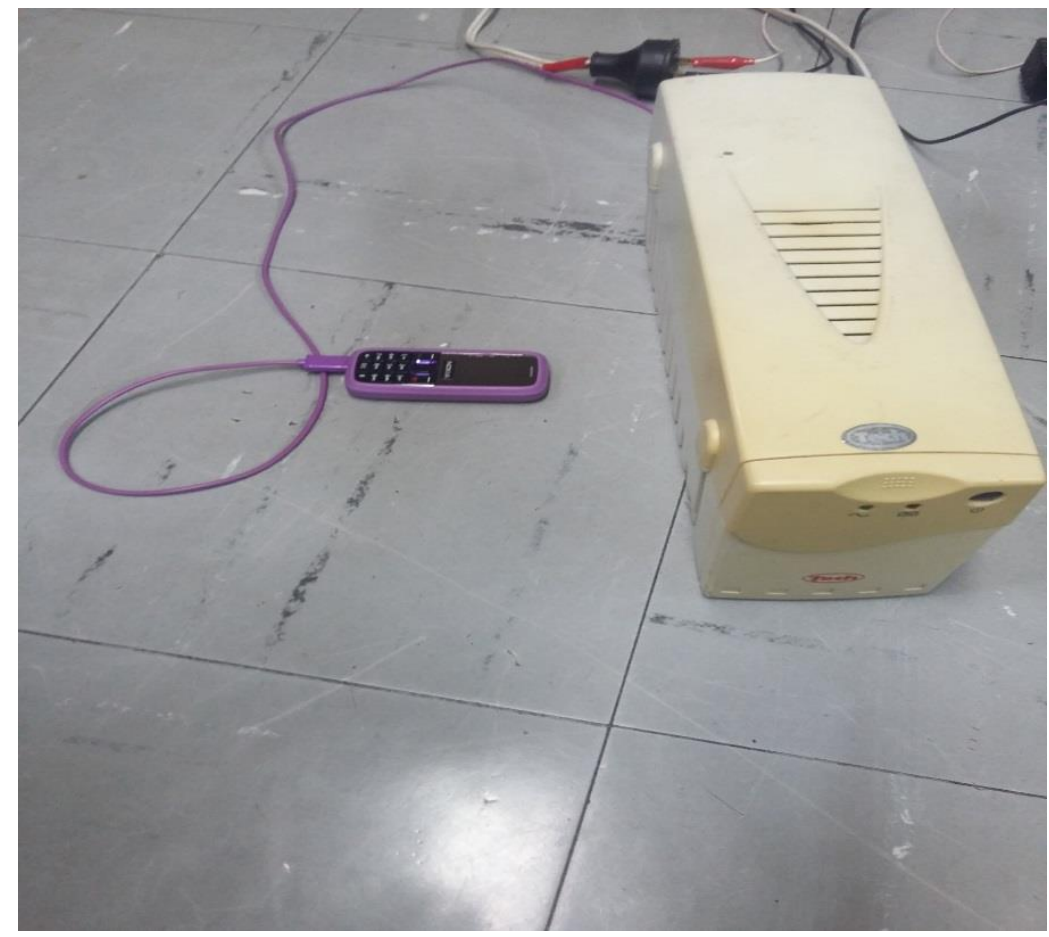

Foto prueba celular Por Diana L. Gutiérrez 